Walter Pohl

\title{
Staat und Herrschaft im Frühmittelalter: Überlegungen zum Forschungsstand
}

\section{STAATSBEGRIFF UND FRÜHMITTELALTERLICHE REGNA}

Daß es im Früh- und Hochmittelalter keinen Staat im modernen Sinn gab, darüber besteht in der Forschung weitgehende Einigkeit. Dennoch wird der mittelalterliche Staat meist am modernen gemessen, vor allem um die Unterschiede hervorzustreichen. In Geschichten des abendländischen Staates stehen die frühmittelalterlichen Königreiche am Beginn einer Entwicklung, die erst später mit Bürokratie und Gewaltmonopol, Souveränität und Staatstheorie, Staatsbürgerschaft und Gewaltenteilung die wesentlichen Elemente moderner Staaten hervorbrachte. Die Einschätzungen gehen dabei nur insoweit auseinander, als manche Autoren im Früh- und Hochmittelalter diese Elemente bereits in Ansätzen entdecken, während andere in jener Zeit geradezu das Gegenbild des modernen europäischen Staates finden. Die „Germanic kingdoms“ des Frühmittelalters, so meinte Joseph Strayer 1970 in seinem in den USA sehr einflußreichen Buch über die mittelalterlichen Ursprünge des modernen Staates, seien „in some ways the complete antithesis of the modern state“. ${ }^{1}$ In dieser Einschätzung treffen sich ganz unterschiedliche Strömungen in der Historiographie des 20. Jahrhunderts, die frühmittelalterliche Staatlichkeit recht gering bewerten. Sie heben sich damit von traditionellen verfassungsgeschichtlichen Positionen des 19. Jahrhunderts ab, die sich vor allem für den Institutionenbau und das Rechtsgefüge des mittelalterlichen Staates interessierten und die Staatlichkeit des Frühmittelalters meist zu positiv beurteilten. ${ }^{2}$ Dabei wurden moderne Verfassungsvorstellungen in die Vergangenheit projiziert, wie Otto Hintze um 1930 zeigte. ${ }^{3}$ Die rechtshistorisch orientierte Forschung überschätzte im allgemeinen die Wirkkraft von Kollektivsubjekten und idealtypischen Kategorien (Staat, Volk, Recht, Königtum etc.).

Die Reaktion auf diese etatistische Sicht der Vergangenheit warf die Frage auf, ob man den Begriff ,Staat' für das Mittelalter nicht besser ganz vermeiden sollte. Oft wurde darauf verwiesen, daß ein zeitgenössisches Wort für ,Staat' gar nicht existierte, und status mit seinen Ableitungen sich erst in der Vor- und Frühmoderne der heutigen Bedeutung näherte. ${ }^{4}$ Doch ist es unvermeidlich, daß wir unseren Begriff nach modernen Kriterien bilden und damit von den Vorstellungen der jeweiligen Zeitgenossen abstrahieren. Das hat bereits Max Weber sehr klar formuliert: „Der wissenschaftliche Staatsbegriff, wie immer er formuliert werde, ist nun natürlich stets eine Synthese, die wir zu bestimmten Erkenntniszwecken vornehmen. Aber er ist andererseits auch abstrahiert aus den unklaren Synthesen, welche in den Köpfen der historischen Menschen vorgefunden werden. Der konkrete Inhalt aber, den der historische ,Staat' in jenen Synthesen der Zeitgenossen annimmt, kann wiederum

1 Joseph R. Strayer, On the Medieval Origins of the Modern State (Princeton 1970) 13; 15. Für Hinweise und Korrekturen zu diesem Artikel danke ich Stuart Airlie, Hans-Werner Goetz, Mayke de Jong, Helmut Reimitz und Pavlina Rychterová.

2 Z. B. (wenn auch in manchem durchaus differenziert) Georg Waitz, Deutsche Verfassungsgeschichte, 6 Bde. (Berlin, ND 1953-55; der 1. Band erschien erstmals 1844); Georg von Below, Der deutsche Staat des Mittelalters (Berlin 1914). Zur Forschungs- und Begriffsgeschichte: Ernst-Wolfgang Böckenförde, Die deutsche verfassungsgeschichtliche Forschung im 19. Jahrhundert. Zeitgebundene Fragestellungen und Leitbilder (Berlin ${ }^{2} 1995$ ); Reinhard Koselleck/Werner Conze u. a., Staat und Souveränität, in: Geschichtliche Grundbegriffe 6, ed. Otto Brunner u. a. (Stuttgart 1990) 1-153.

3 Otto Hintze, Wesen und Wandlung des modernen Staates, in: ders., Staat und Verfassung. Gesammelte Abhandlungen zur modernen Verfassungsgeschichte, ed. Gerhard Oestreich (Göttingen ${ }^{3} 1970$, Erstveröffentl. 1931) 470-496.

4 Ausführlich jüngst Alan Harding, Medieval Law and the Foundation of the State (Oxford 2002). 
nur durch Orientierung an idealtypischen Begriffen zur Anschauung gebracht werden."5 Allerdings laufen „die als geltend oder geltensollend geglaubte praktische Idee“ und der „zu Erkenntniszwecken konstruierte Idealtypus“ nebeneinander her und neigen dazu, ineinander überzugehen- auch bei modernen mediävistischen Debatten.

Die in der Literatur gebotenen Definitionen des Staatsbegriffes sind außerordentlich unterschiedlich. Um nur wenige Beispiele zu nennen: Man kann Staat von der Staatsgewalt her definieren, etwa im Sinne Max Webers durch das „Monopol legitimen physischen Zwanges“; der mittelalterliche Staat ist dann kaum darunter zu verstehen. ${ }^{6}$ Ernest Gellner hat, an Weber anknüpfend, das Element des Gewaltmonopols mit der gesellschaftlichen Arbeitsteilung verknüpft; Staat exisitiert dort, wo sich Ordnungsgewalten herausdifferenziert haben, was er ausdrücklich auch für vormoderne Gesellschaften annimmt. ${ }^{7}$ Man kann auf den Staatszweck abheben, etwa Schutz nach innen und nach außen; das würde Gemeinwesen bis weit in die Vorgeschichte hinein mit erfassen. Möglich ist auch eine Definition nach Organisationsgrad und Abstraktionsniveau, wie bei Quentin Skinner ,as a form of public power separate from both the ruler and the ruled" . ${ }^{8}$ Oder man versucht das Verhältnis von Herrschenden und Beherrschten als wesentliches Kriterium zu erfassen. ${ }^{9}$ In der Konvention von Montevideo 1933 wurde eine dreigliedrige Definition angenommen: „A political community formed by a territorially defined population which is subject to one government“. In gängigen politikwissenschaftlichen Einführungen erscheinen diese drei Elemente weiterhin als „core features of states“, eventuell ergänzt um die Fähigkeit, mit anderen Staaten Beziehungen einzugehen. ${ }^{10}$

Diese ziemlich formalen Definitionen können, ebenso wie Otto Hintzes Kriterium, nämlich die gemeinsame Willensbildung, problemlos auf frühmittelalterliche Verhältnisse übertragen werden. ${ }^{11}$ Dagegen gibt es spezifischere Definitionen, die ihre Kriterien vom modernen souveränen Staat mit Bürokratie und Gewaltmonopol ableiten. Strayers Definition des Staates ist dafür ein gutes Beispiel: „Political units persisting in time and fixed in space, the development of permanent, impersonal institutions, agreement on a need for an authority which can give final judgements, and acceptance of the idea that this authority should receive the basic loyalty of its subjects" ${ }^{12}$ Immerhin, die Stabilität in Zeit und Raum, ein sehr nützliches Kriterium, war bei den Regna des Früh- und Hochmittelalters fast ebenso weitgehend verwirklicht wie heute. Und die Idee einer Autorität, die letztgültig urteilen und grundsätzlich Loyalität beanspruchen kann, war dem Mittelalter ebensowenig fremd, sieht man von der Frage der Durchsetzbarkeit solcher Urteile ab. Schwieriger wird es bei den ,unpersönlichen Institutionen', wo der Diskussionsspielraum allerdings beträchtlich ist, wie noch zu zeigen sein wird.

Kompliziert wird der Befund durch die Frage nach den Vorformen des modernen Staates in mittelalterlichen Institutionen und Begriffen. ${ }^{13}$ Sie hat sehr differenzierte Ergebnisse erbracht, trägt aber unausweichlich eine teleologische Orientierung mit sich und behindert daher eine jeweils zeitgemäße Betrachtungsweise früherer Staaten. Die Rezeption des römischen Rechts und der aristotelischen Staatslehre im späteren Mittelalter, die Ausgliederung der Justiz aus der Verwaltung, die Be-

5 Max Weber, Die Objektivität sozialwissenschaftlicher Erkenntnis, in: ders., Soziologie. Universalgeschichtliche Analysen. Politik, ed. Johannes Winckelmann (Stuttgart ${ }^{6}$ 1992) 186-262, hier 246.

${ }^{6}$ Max Weber, Wirtschaft und Gesellschaft. Grundzüge der verstehenden Soziologie (Tübingen $\left.{ }^{5} 1976\right) 124$.

7 Ernest Gellner, Nations and Nationalism (Oxford 1983) 4: „The state exists where specialised order-enforcing agencies, such as police force and courts, have separated out from the rest of social life."

8 Quentin Skinner, Foundations of Modern Political Thought, 2 Bde. (Cambridge 1978), hier Bd. 2, 353-355.

9 Harding, Medieval Law 2.

${ }^{10}$ Rod Hague/Martin Harrop, Comparative Government and Politics. An Introduction (Basingstoke/New York $\left.{ }^{5} 2001\right) 6$.

11 Hintze, Wesen; vgl. Conze, Staat und Souveränität 6.

12 Strayer, Origins 10. Spezifisch für frühmittelalterliche Staaten zuletzt Chris Wickham, Framing the Early Middle Ages. Europe and the Mediterranean, 400-800 (Oxford 2005) 57: „the centralisation of legitimate enforcable authority“, „the spezialisation of government roles“, „the concept of a public power“, „independent and stable resources for rulers“, und „,a class based system of surplus extraction".

13 Siehe z. B. Wolfgang Reinhard, Geschichte der Staatsgewalt (München 1999); L'état moderne: Genèse (Bilan et perspectives), ed. Jean-Philippe Genet (Paris 1990), mit dem Überblick über ein größeres Forschungsprojekt der achtziger Jahre, das die Zeit vom 13. bis zum 18. Jahrhundert behandelte. 
deutungsverschiebung des Begriffes ,Staat', die Durchsetzung des staatlichen Gewaltmonopols und die Entfaltung des Souveränitätsbegriffes in der frühen Neuzeit markieren dabei wesentliche Etappen in der Staatsentwicklung. Im Frühmittelalter finden sich, vom Standpunkt der Genese des modernen Staates betrachtet, allenfalls Vor- oder Kümmerformen davon. Wie weit die neuzeitliche Verdichtung des Staates auf einer Wiederaufnahme eines im Frühmittelalter verlorenen antiken Verständnisses von Staat und öffentlicher Ordnung beruhte, wurde unterschiedlich eingeschätzt. ${ }^{14}$ Umstritten war auch, ob bereits der Untergang Roms und die Barbareninvasionen eine frühmittelalterliche Krise des Staates auslösten, oder ob erst der Zerfall des Karolingerreiches einen Tiefpunkt im 10. und frühen 11. Jahrhundert zur Folge hatte, was sich in einem Großteil der neueren Mediävistik durchgesetzt hat. ${ }^{15}$ Ein anderer Akzent wurde von einer Richtung in der englischen Forschung gesetzt, wo James Campbell und andere die außerordentliche Zentralisierung des angelsächsischen Staates im 10. und 11. Jahrhundert hervorgehoben haben. ${ }^{16}$ In Untersuchungen der modernen Staatsentwicklung werden meist die institutionelle Festigkeit und der transpersonale Charakter des modernen Staates, oft auch des römischen Reiches überschätzt, die Integrationsfähigkeit frühmittelalterlicher Regna hingegen unterschätzt.

Die Skepsis gegenüber der Annahme eines mittelalterlichen Staates hat auch in der deutschen Mittelalterforschung Tradition. Die Herrschaftslehre der Mitte des 20. Jahrhunderts (damals „Neue Deutsche Verfassungsgeschichte“ genannt) suchte statt Rechtsnormen und staatlichen Institutionen ein persönliches und konkretes Ordnungsgefüge..$^{17}$ Diese Konkretheit fand man im Volk als Gemeinschaft, als Personenverband, dessen Verfassung als „Gesamtheit der Einrichtungen, die das Leben in der Gemeinschaft ermöglichen“, weit über den ,staatlichen“ Bereich hinausgriff. ${ }^{18}$ Die Verfassung war demnach durch Herrschaft geprägt, die als persönliches Unterordnungsverhältnis verstanden wurde, aber auch als ständische Ordnung, in der ein alter Adel seine Herrschaftsrechte wahrnehmen konnte; Königtum und Staat waren zunächst nur Steigerungsformen dieser Adelsherrschaft. Als persönliche Beziehung beruhte Herrschaft auf einer Reihe von moralisch aufgeladenen Bindungsformen und Verhaltensprägungen wie Gefolgschaft, Schutz und Schirm, Ehre, Treue und Huld. Theodor Mayers Begriff vom „Personenverbandsstaat“ schuf eine elastische Verbindung zu stärker rechtshistorisch orientierten Positionen. ${ }^{19}$

Die Überwindung einer vom modernen Staatsverständnis in die Vergangenheit projizierten Terminologie und der Versuch, die ,Verfassung' in der Begrifflichkeit der Zeit zu beschreiben, eröffneten neue Forschungsperspektiven. Das Problem lag freilich gerade in der scheinbaren Konkretheit der

14 Ausführlich zuletzt Harding, Medieval Law.

15 Überblick über die ältere Debatte: Giovanni Tabacco, La dissoluzione medievale dello stato nella recente storiografia, in: Studi medievali, ser. 3, 1 (1960) 397-446, oder in: ders., Sperimentazioni del potere nell'alto medioevo (Turin 1993) $245-303$.

16 James Campbell, The Anglo-Saxon State (Hambledon/London 2000); siehe den Beitrag von Patrick Wormald, in diesem Band. Überblick über die englischsprachige Forschung zum mittelalterlichen Staat: Susan Reynolds, The historiography of the medieval state, in: Companion to Historiography, ed. Michael Bentley (London/New York 1997) 117-138. Zum Vergleich mit gleichzeitigen Verhältnissen auf dem Kontinent: Timothy Reuter, König, Adelige, Andere: ,Basis‘ und ,Überbau` in ottonischer Zeit, in: Ottonische Neuanfänge, ed. Bernd Schneidmüller/Stefan Weinfurter (Mainz 2001) 127-150, hier 130f.

17 Zahlreiche grundlegende Arbeiten sind in überarbeiteter Form versammelt in: Herrschaft und Staat im Mittelalter, ed. Hellmut Kämpf (Wege der Forschung 2, Darmstadt 1956); besonders Otto Brunner, Moderner Verfassungsbegriff und mittelalterliche Verfassungsgeschichte (1-19); erstveröffentl. in: MIÖG Erg.Bd. 14 (1939) 513-528, und Theodor Mayer, Die Ausbildung der Grundlagen des modernen Staates im hohen Mittelalter, in: Herrschaft und Staat im Mittelalter, ed. Hellmut Kämpf (Wege der Forschung 2, Darmstadt 1956) 284-331, erstveröffentlicht in: Historische Zeitschrift 159 (1939) $457-487$. Siehe auch Hans-Werner Goetz, Moderne Mediävistik. Stand und Perspektiven der Mittelalterforschung (Darmstadt 1999) 180-185. Eine ausführliche Diskussion dieser Positionen kann hier nicht geboten werden, siehe dazu Walter Pohl, Herrschaft, in: RGA 2. Aufl. 14 (1999) 443-457, sowie die Beiträge von Hans-Werner Goetz und Steffen Patzold, in diesem Band.

18 Walter Schlesinger, Verfassungsgeschichte als Landesgeschichte, in: ders., Beiträge zur deutschen Verfassungsgeschichte des Mittelalters 2 (Göttingen 1963) 9-41, hier 11 f.; ders., Die Grundlegung der deutschen Einheit im frühen Mittelalter, in: ebd. 245-285 und 346-348, hier 284: „Das Primäre ist nicht das deutsche Reich, sondern das deutsche Volk“. Dazu Carlrichard Brühl, Deutschland - Frankreich. Die Geburt zweier Völker (Köln/Wien 1990) 710.

19 „Der germanische und der frühe deutsche Staat war ein Volksstaat, er beruhte primär nicht auf der Herrschaft über ein Gebiet, sondern auf einem Verband von Personen." Mayer, Ausbildung 289. 
neugewonnenen Bestimmungen. Auch ,Volk‘ ist ein Abstraktum, dessen zeitgenössische Definition als Abstammungsgemeinschaft erst die neuere Forschung als Fiktion erkannt hat. ${ }^{20}$ Die jeweilige Verfassung war nicht authentischer Ausdruck eines Volkscharakters (etwa der „ungeheuren Fähigkeiten für Staat und Kultur" der Germanen ${ }^{21}$ ); eher bestimmte umgekehrt, wie schon Reinhard Wenskus erkannte, das Bekenntnis zu einer Verfassung über die Zugehörigkeit zu einem Stamm oder Volk. ${ }^{22}$ Der weit gefaßte Verfassungsbegriff öffnete den Blick dafür, wie sehr politische Institutionen im sozialen und kulturellen Leben eingebettet waren, verwischte aber leicht wiederum die Besonderheiten politischer Macht, besonders wenn sie ausschließlich aus persönlichen Herrschaftsverhältnissen abgeleitet wurde. Die These von der autogenen germanischen Adelsherrschaft, aus der Reich und Staat quasi naturwüchsig entstehen konnten, hat sich nicht bestätigen lassen. ${ }^{23}$

Schließlich führten gerade die scheinbar quellennahen und lebensgesättigten Begriffe für herrschaftliche Interaktionsformen mit ihrem Anspruch einer Moralisierung von Herrschaft zu einem schweren Quellen- und Methodenproblem: Begriffe wie Treue, Huld, Gefolgschaft (und damit letztlich auch Herrschaft) erlauben es nicht, zwischen Wahrnehmungen, Vorstellungen, Ideologien auf der einen Seite und sozialem Verhalten und Beziehungsmustern auf der anderen Seite zu unterscheiden, da ja der moralische Anspruch in die Begriffsdefinition hereingenommen ist. Ein Diskurs, der Herrschaft legitimieren sollte, wurde fast unvermittelt zur wissenschaftlichen Beschreibung von Herrschaftsstrukturen verwendet. Dadurch, daß ursprünglich mehr oder weniger zeitnahen Quellen entnommene Begriffe im Rahmen einer modernen wissenschaftlichen Terminologie erklärungstüchtig werden sollten, wurden sie zugleich ebenso enthistorisiert, wie man es der modernen Begrifflichkeit gerade vorgeworfen hatte. Das war deswegen methodisch noch schwerwiegender, weil zugleich mit der Authentizität der Quellenbegriffe argumentiert wurde, während deren ganze Vielfalt, Wandelbarkeit und Widersprüchlichkeit aus dem Blick geriet. Mit dem christlich stilisierten Treuebegriff des Hochmittelalters oder den Fehden der isländischen Sagas nähert man sich nicht dem Frühmittelalter, sondern man überdeckt die oft undeutlichen Spuren in zeitgenössischen Quellen mit den kräftigeren Farben späterer Stilisierungen. Der „Primat einer nicht systematisch definierten, sondern gemeinsam geglaubten Verfassungsgeschichte“ ist, wie Bernd Schneidmüller in einem prägnanten Überblick über die Forschungsgeschichte gezeigt hat, vergangen. ${ }^{24}$ Die Methodendiskussion wurde leider nach der fulminanten Kritik von František Graus nie zu Ende geführt. ${ }^{25}$ In der deutschen Me-

20 Forschungsüberblick: Walter Pohl, Tradition, Ethnogenese und literarische Gestaltung: eine Zwischenbilanz, in: Ethnogenese und Überlieferung. Angewandte Methoden der Frühmittelalterforschung, ed. Karl Brunner/Brigitte Merta (Veröffentlichungen des Instituts für Österreichische Geschichtsforschung 31, Wien 1994) 9-26; Patrick J. Geary, Europäische Völker im frühen Mittelalter. Zur Legende vom Werden der Nationen (Frankfurt 2002).

21 Mayer, Ausbildung 286. Ein später Nachzügler eines derartigen völkischen Verfassungsbegriffes ist Ernst Pitz, Die griechisch-römische Ökumene und die drei Kulturen des Mittelalters. Geschichte des mediterranen Weltteils zwischen Atlantik und Indischem Ozean 270-812 (Berlin 2001), bes. 493-95, der im „Staatsgedanken von der Durchschlagskraft des germanischen Konsens- und Genossenschaftsprinzips“ den Grund für den Erfolg des Abendlandes sieht.

${ }^{22}$ Reinhard Wenskus, Stammesbildung und Verfassung. Das Werden der frühmittelalterlichen gentes (Köln/Wien $\left.{ }^{2} 1977\right)$.

23 Grundlegend dafür war Heinrich Dannenbauer, Adel, Burg und Herrschaft bei den Germanen, in: Historisches Jahrbuch 61 (1941) 1-50, und in: Herrschaft und Staat, ed. Kämpf 60-134. Zur Diskussion u. a.: Matthias Werner, Adelsfamilien im Umkreis der frühen Karolinger. Die Verwandtschaft Irminas von Oeren und Adelas von der Pfalzel. Personengeschichtliche Untersuchungen zur frühmittelalterlichen Führungsschicht im Maas-Moselraum (Sigmaringen 1982); Hans-Werner Goetz, Nobilitas. Der Adel im Selbstverständnis der Karolingerzeit, in: Vierteljahresschrift für Sozial- und Wirtschaftsgeschichte 70 (1983) 153-191; Karl Ferdinand Werner, Naissance de la noblesse. L'essor des élites politiques en Europe (Paris 1998); Igor Mineo, Di alcuni usi della nobilità medievale, in: Storica 20/21 (2001) 9-58 (ausführliche Rezeption der deutschen Adelsforschung seit 1939).

24 Bernd Schneidmüller, Von der deutschen Verfassungsgeschichte zur Geschichte politischer Ordnungen und Identitäten im europäischen Mittelalter, in: Zeitschrift für Geschichtswissenschaft 53 (2005) 485-500, hier 487.

25 Von Seite der ,neuen Verfassungsgeschichte‘: Walter Schlesinger, Randbemerkungen zu drei Aufsätzen über Sippe, Gefolgschaft und Treue, in: Alteuropa und die moderne Gesellschaft. Festschrift für Otto Brunner, red. Alexander Bergengruen/ Ludwig Deike (Göttingen 1963) 11-59. Kritisch u. a.: František Graus, Herrschaft und Treue, in: Historica 12 (1966) 5-44; ders., Verfassungsgeschichte des Mittelalters, in: Historische Zeitschrift 243 (1986) 529-589; siehe auch insgesamt ders., Ausgewählte Aufsätze, ed. Hans-Jörg Gilomen/Peter Moraw/Rainer C. Schwinges (Vorträge und Forschungen 55, Stuttgart 2002); Karl Kroeschell, Die Treue in der deutschen Rechtsgeschichte, in: Studi medievali, ser. 3, 10 (1969) 465-489; Walther 
diävistik ist (abgesehen vom Fortwirken eines positivistisch-verfassungsgeschichtlichen Zuganges) der grundlegende Ansatz der ,Neuen Deutschen Verfassungsgeschichte', die herrschaftlichen Ordnungen von Personenverbänden zu untersuchen, weiterhin verbreitet. Der Bezug auf das germanischdeutsche Volk, ,seine ' Verfassung und seine Sekundärtugenden ist jedoch weitgehend obsolet geworden.

Die Skepsis gegenüber dem Staatsbegriff ist in der neueren deutschen Mittelalterforschung weiterhin verbreitet. Johannes Fried hat in seinem ebenso einflußreichen wie kontroversiellen Aufsatz über „Wahrnehmungs- und Deutungskategorien politischen Wandels im Frühmittelalter" darauf hingewiesen, daß „Staat ein theorieberstendes Deutungsschema ist, dessen Anwendung allein schon eine bestimmte Perspektive aufnötigt“ ${ }^{26}$ Solche Skepsis folgt aus der Einsicht in die „doppelte Theoriebindung des Historikers", der sowohl damalige als auch heutige Deutungen an seinen Stoff heranträgt. ,Staat', ,Volk‘, ,Recht', ,Kultur' und ähnliches waren, wie Fried herausarbeitet, für die Zeitgenossen ebensowenig direkt wahrnehmbar, wie sie es für moderne Historiker sind; es handelt sich vielmehr um Metaphern, um komplexe Deutungsfiguren, die ein bestimmtes, selbst wieder veränderbares soziales Wissen voraussetzen. Im Sinn von Jan Assmann wären sie damit Gegenstand einer Sinngeschichte sozialer Gemeinschaften. ${ }^{27}$ Auf diese Ebene des zeitgenössischen Wissens um gesellschaftliche Kategorien zielt auch der von Hans-Werner Goetz in diesem Band vorgestellte Ansatz einer Geschichte der Vorstellungen. Ob man nun von Geschichte des Wissens, der Wahrnehmungen, der Vorstellungen oder von Sinngeschichte spricht, unterscheidet sich in mancher Hinsicht. Doch dürfte weitgehend Konsens darüber bestehen, daß die Untersuchung vergangener Wahrnehmungen und Sinnformationen sich nicht im herkömmlichen Sinn auf Ideengeschichte beschränkt, sondern zugleich auf die sozialen und politischen Verhältnisse zielt, also gedachte und gelebte Ordnungen zusammendenkt. ${ }^{28}$ Einen entscheidenden Fortschritt gegenüber der älteren Forschung bietet Frieds Arbeit ebenso wie ähnliche Ansätze dadurch, daß das Eigengewicht der Texte gegenüber der Realität, die sie beschreiben, in den Blick gerät. Das muß nicht zu einer rein textzentrierten Betrachtungsweise im Sinne des ,literary turn' der 1980er Jahre führen. ${ }^{29}$ Der Text ist ja, mitsamt den darin ausgedrückten und propagierten Vorstellungen, selbst Teil der vergangenen Realität, die es zu untersuchen gilt.

Freilich löst das noch nicht die Frage, wie vergangene Verhältnisse denn nun zu beschreiben sind. Soll man auf ,theorieberstende“ Begriffe wie ,Volk' und ,Staat' gänzlich verzichten? Das Webersche Spannungsverhältnis zwischen ,Idealtypen “ und ,geglaubten praktischen Begriffen` auflösen? Der Rekurs auf Quellenbegriffe, den die ,Neue Deutsche Verfassungsgeschichte' zum Programm gemacht hatte, hat sich als Alternative nicht bewährt. Selbst wo sie weniger wertend sind als ,Treue' oder ,Huld', ist ein Auseinanderklaffen von Quellenbedeutung und modernem Begriffsinhalt unvermeidlich. Das heißt nicht, daß Quellenbegriffe gar nicht mehr verwendet werden sollten, solange ihnen nicht zu große Erklärungslast aufgebürdet wird. Sicherlich ist es sinnvoll, von Regna statt von Germanenreichen, von Leges statt von Germanenrechten zu sprechen (womit zugleich der im Frühmittel-

Kienast, Germanische Treue und Königsheil, in: Historische Zeitschrift 227 (1978) 265-324; Gadi Algazi, Herrengewalt und Gewalt der Herren im späten Mittelalter: Herrschaft, Gegenseitigkeit und Sprachgebrauch (Frankfurt am Main 1996), eine Kritik des grundlegenden Werkes von Otto Brunner, Land und Herrschaft. Grundfragen der territorialen Verfassungsgeschichte Österreichs im Mittelalter (Wien ${ }^{5} 1965$, ND Darmstadt 1990, Erstveröffentl. 1939); vgl. aber auch die Kritik an Algazi von Sigrid Schmitt, Schutz und Schirm oder Gewalt und Unterdrückung? Überlegungen zu Gadi Algazis Dissertation „Herrengewalt und Gewalt der Herren im späten Mittelalter“, in: Vierteljahresschrift für Sozial- und Wirtschaftsgeschichte 98 (2002) 72-78.

26 Johannes Fried, Gens und regnum. Bemerkungen zur doppelten Theoriebindung des Historikers, in: Sozialer Wandel im Mittelalter. Wahrnehmungsformen, Erklärungsmuster, Regelungsmechanismen, ed. Jürgen Miethke/ Klaus Schreiner (Sigmaringen 1994) 73-104, hier 98.

27 Jan Assman, Ägypten - eine Sinngeschichte (Frankfurt am Main 1999); Walter Pohl, Identität und Widerspruch. Gedanken zu einer Sinngeschichte des Frühmittelalters, in: Die Suche nach den Ursprüngen. Von der Bedeutung des frühen Mittelalters, ed. ders. (Forschungen zur Geschichte des Mittelalters 9, Wien 2004) 23-35.

28 Vgl. Stefan Weinfurter, Gelebte Ordnung - gedachte Ordnung. Ausgewählte Beiträge zu König, Kirche und Reich (Sigmaringen 2005); Schneidmüller, Von der deutschen Verfassungsgeschichte zur Geschichte politischer Ordnungen 499, der auch auf die Obertöne des Ordnungsbegriffes hinweist.

${ }^{29}$ Walter Pohl, History in fragments. Montecassino's politics of memory, in: Early Medieval Europe 10, 3 (2001) 343-74. 
alter problematische Germanenbegriff vermieden wird ${ }^{30}$ ). Doch bleibt das eine prekäre Hilfskonstruktion. Zum einen suggeriert auch sie gewisse Deutungsmuster (ebenso wie die ,Neue Deutsche Verfassungsgeschichte“ durch die Verwendung deutscher Quellenbegriffe germanische Kontinuität unterstreichen wollte, legt die lateinische Begriffswahl römische Kontinuität nahe), zum anderen sind die verwendeten Quellenbegriffe widersprüchlich. Das läßt sich gut am Beispiel von gens zeigen, was die Agilolfinger ebenso wie die Bayern beschreiben konnte. Und der Bedeutungsumfang von regnum war in der Kontroverse zwischen Hans-Werner Goetz und Johannes Fried ja der Hauptstreitpunkt. ${ }^{31}$

Frieds Dekonstruktion des karolingischen Staates findet den Zusammenhalt des regnum Francorum letztlich in der Person des Königs begründet. Diesem fehlt ebenso wie den gelehrten Zeitgenossen jedes ,Staats'-Bewußtsein, sein Handeln „ist vielmehr durch dessen Fehlen bedingt“, was zu fatalen Fehleinschätzungen, „einer Fülle von Niederlagen und Katastrophen“ führt. ${ }^{32}$ Dadurch wird erst allmählich ein teuer erkaufter Lernprozeß möglich, der letztlich zu einer Art ursprünglicher Akkumulation des Staats-Denkens führt. Im polemischen Genre, dessen Fried sich hier bedient, wird die Unangemessenheit politischen Handelns karolingischer Herrscher ebenso wie die Personalität ihrer Herrschaft natürlich zugespitzt, mehr als es seine ausführliche Darstellung im monumentalen „Weg in die Geschichte" tut. ${ }^{33}$ Daß im Frankenreich die Ecclesia als Gemeinschaft der Gläubigen in viel höherem Maß Ziel und Inbegriff von Ordnungsstreben war als die weltliche Hierarchie, ist zweifellos richtig. ${ }^{34}$ Rudolf Schieffer hat vor kurzem auf der Reichenau gezeigt, daß politische Integration im Karolingerreich weniger durch gezielte staatliche Einheitsbestrebungen gelang als (abgesehen von „nüchternem Machtkalkül“") durch das Bemühen um Vereinheitlichung des kirchlichen Lebens..$^{35}$ Doch wie grundlegend, so fragt Mayke de Jong in diesem Band, war der Unterschied zwischen Ecclesia und weltlichem Herrschaftsverband, zwischen fränkischer Gens und christlichem Populus wirklich? ${ }^{236}$ Modell für die Ausbildung des christlichen Herrscherethos des Frühmittelalters, das hat Nikolaus Staubach gezeigt, war die Konzeption des kirchlichen Leitungsamtes. ${ }^{37}$ Denken wir nicht immer noch zu stark in der Tradition der modernen Abgrenzung von Kirche und Staat? Tatsächlich ist der Zusammenhang der frühmittelalterlichen Regna ohne die Ecclesia gar nicht denkbar, was sich schon daran ablesen läßt, daß es kein Beispiel für dauerhafte politische Integration ohne kirchliche Ordnung im mittelalterlichen Europa gibt; Sachsen, Dänen oder Polen, letztlich auch Ungarn oder Bulgaren gelang der Aufbau stabiler zentralisierter Herrschaft erst nach der Christianisierung. Das muß nicht als

30 Walter Pohl, Der Germanenbegriff vom 3. bis 8. Jahrhundert - Identifikationen und Abgrenzungen, in: Zur Geschichte der Gleichung ,germanisch - deutsch', ed. Heinrich Beck/Dieter Geuenich/Heiko Steuer/Dietrich Hakelberg (RGA Erg.Bd. 34, Berlin/New York 2004) 163-183.

31 Hans-Werner Goetz, Regnum. Zum politischen Denken der Karolingerzeit, in: Zeitschrift der Savigny-Stiftung für Rechtsgeschichte, Germanistische Abteilung 104 (1987) 110-189; Fried, Gens und Regnum; Matthias Becher, Volksbildung und Herzogtum in Sachsen während des 9. und 10. Jahrhunderts, in: MIÖG 108 (2000) 67-84, Hans-Werner Goetz, GENTES. Zur zeitgenössischen Terminologie und Wahrnehmung ostfränkischer Ethnogenese im 9. Jahrhundert, in: ebd. 85-116; siehe auch den Beitrag von Hans-Werner Goetz, in diesem Band; Jörg Jarnut, Anmerkungen zum Staat des frühen Mittelalters. Die Kontroverse zwischen Johannes Fried und Hans-Werner Goetz, in: Akkulturation. Probleme einer germanisch-romanischen Kultursynthese in Spätantike und frühem Mittelalter (RGA Erg.Bd. 41, Berlin/New York 2004) 504-509.

32 Fried, Gens und regnum 101.

33 Johannes Fried, Der Weg in die Geschichte - bis 1024 (Propyläen Geschichte Deutschlands 1, Berlin 1994).

34 So schon Johannes Fried, Der karolingische Herrschaftsverband im 9. Jahrhundert zwischen ,Kirche“ und ,Königshaus', in: Historische Zeitschrift 235 (1982) 1-43; vgl. auch Nikolaus Staubach, ,Cultus divinus‘ und karolingische Reform, in: Frühmittelalterliche Studien 18 (1984) 546-581; Arnold Angenendt, Karl der Große als ,rex et sacerdos', in: Das Frankfurter Konzil von 794. Kristallisationspunkt karolingischer Kultur 1, ed. Rainer Berndt (Frankfurt 1997) 255-78.

35 Rudolf Schieffer, Die Einheit des Karolingerreiches als praktisches Problem und als theoretische Forderung, in: Fragen der politischen Integration im mittelalterlichen Europa 1: Früh- und Hochmittelalter, ed. Werner Maleczek (Arbeitstagung auf der Insel Reichenau 2002, Vorträge und Forschungen 63, Ostfildern 2005) 33-47. Ich danke Rudolf Schieffer und Werner Maleczek für die Überlassung des Manuskriptes. Vgl. auch den Überblick bei Rudolf Schieffer, Die Zeit des karolingischen Großreichs, 714-887 (Gebhardt. Handbuch der deutschen Geschichte 2, Stuttgart $\left.{ }^{10} 2005\right) \S \S 14$ und 15.

${ }^{36}$ Mayke de Jong, The empire as ecclesia: Hrabanus Maurus and biblical historia for rulers, in: The Uses of the Past in the Early Middle Ages, ed. Yitzhak Hen/Matthew Innes (Cambridge 2000) 191-226; siehe auch ihren Beitrag in diesem Band.

37 Nikolaus Staubach, Signa utilia - signa inutilia. Zur Theorie gesellschaftlicher und religiöser Symbolik bei Augustinus und im Mittelalter, in: Frühmittelalterliche Studien 36 (2002) 19-49. 
Unreife frühmittelalterlicher Staatlichkeit interpretiert werden; man kann darin auch ein ehrgeiziges und hartnäckiges Bemühen um die ethische Ausgestaltung des politischen Zusammenhaltes sehen, dessen Intensität meist unterschätzt wird.

Das führt zum Kernproblem, wie Ordnung und Zusammenhalt früh- und hochmittelalterlicher Regna eigentlich konzeptionell zu erfassen sind, der Frage „nach den Abläufen und Mechanismen, welche diese Reiche zu handlungsfähigen Einheiten werden ließen“. ${ }^{38} \mathrm{Ob}$ man dafür den Begriff Staat verwendet oder nicht, ist letztlich nicht entscheidend. Um „segmentäre Gesellschaften“ handelt es sich bei den frühmittelalterlichen Königreichen ganz sicher nicht. ${ }^{39}$ Sie müssen in ihrem Systemcharakter erfaßt werden, und wer sie nicht als (wenn auch vormoderne) Staaten darstellen will, muß für ihren Gesamtzusammenhang eine Alternative bieten: Wie konnte das Frankenreich über viele Jahrhunderte hinweg großräumige Herrschaft bewahren und die Kontinuität all seiner wesentlichen Institutionen - Königtum, weltliche und geistliche Ämter, sowie Rechte und Besitzungen von Grundherren, Kirchen und Klöstern - garantieren?

Hier liegt freilich ein breiter Interpretationsspielraum vor. Zugleich ist Erfolg oder Scheitern von Herrschaftsansprüchen ein Kernpunkt jeder Diskussion über frühmittelalterliche Staatlichkeit. Ist unzureichende Herrschaftsdurchsetzung ein Zeichen für mangelnde Kohärenz und niedrige Entwicklungsstufe einer Gesellschaft (siehe Abschnitt 4)? Nennen wir ,Staat' nur jene politischen Einheiten, deren Herrscher gemäß der Herrschaftsdefinition Max Webers ${ }^{40}$ eine hohe Chance hatten, für ihre Befehle im ganzen Reich Gehorsam zu finden? Um nur ein Beispiel zu nennen: „Aktualität und Effektivität" karolingischer Kapitularien, und damit das Ausmaß des Gehorsams gegenüber schriftlichen Befehlen karolingischer Herrscher, wird oft als Kriterium für Erfolg oder Scheitern karolingischer Staatlichkeit betrachtet. ${ }^{41}$ Diese Diskussion betrifft einen wichtigen Aspekt in der Beurteilung karolingerzeitlicher Herrschaftspraxis. Manches spricht dafür, daß frühmittelalterliche Gesetzgebung zunächst der Repräsentation des Herrschers diente und ihre flächendeckende Durchsetzung auf mehr oder weniger unüberwindliche Hindernisse stieß. ${ }^{42} \mathrm{Zu}$ denken gibt auch, „daß der karolingische Versuch, Herrschaft mittels Schriftlichkeit zu organisieren und zu intensivieren, Episode blieb". ${ }^{43}$ Doch wäre ,Staat' nicht auch der politische Raum zu nennen, an dem sich solche Entwürfe einheitlichen und reglementierten Handelns orientierten, soweit zumindest der Versuch der politischen Durchsetzung unternommen wurde? Wenn Erfolg oder Scheitern der Herrschaftsdurchsetzung Kriterium für das Vorhandensein von Staatlichkeit sind, wäre es streng genommen möglich, daß ein Staat unter einem erfolgreichen Herrscher bestand und beim nächsten Thronkonflikt wieder erlosch. Ob ,Staatlichkeit' sich an der Durchsetzung von Herrschaft messen läßt, kommt auch darauf an, ob man einen obrigkeitlich gefärbten Staatsbegriff verwendet oder einen, der den Konsens betont. ${ }^{44}$ In Deutschland

38 Hagen Keller, Die Investitur. Ein Beitrag zum Problem der Staatssymbolik im Hochmittelalter, in: Frühmittelalterliche Studien 27 (1993) 51-86, hier 53.

39 Gesellschaften ohne Staat, Bd. 1: Gleichheit und Gegenseitigkeit, Bd. 2: Genealogie und Solidarität, ed. Fritz Kramer/Christian Sigrist (Frankfurt am Main 1978); siehe unten.

40 Max Weber, Die drei reinen Typen der legitimen Herrschaft, in: ders., Soziologie. Universalgeschichtliche Analysen. Politik, ed. Johannes Winckelmann (Stuttgart $\left.{ }^{6} 1992\right)$ 151-166, hier 151.

${ }^{41}$ Hermann Nehlsen, Zur Aktualität und Effektivität germanischer Rechtsaufzeichnungen, in: Recht und Schrift im Mittelalter, ed. Peter Classen (Vorträge und Forschungen 23, Sigmaringen 1977) 449-502; Hubert Mordek, Studien zur fränkischen Herrschergesetzgebung. Aufsätze über Kapitularien und Kapitulariensammlungen ausgewählt zum 60. Geburtstag (Frankfurt am Main 2000). Zur karolingischen Regierung siehe zuletzt Matthew Innes, Charlemagne's government, in: Charlemagne - Empire and Society, ed. Joanna Story (Manchester/New York 2005) 71-89.

42 Patrick Wormald, The Making of English Law: King Alfred to the $12^{\text {th }}$ Century 1: Legislation and its Limits (Oxford 1999); ein stärkerer Akzent auf pragmatischem Gebrauch der Gesetze: Philippe Depreux, La loi et le droit. La part des échanges culturels dans la référence à la norme et les pratiques juridiques durant le haut Moyen Age, in: Les échanges culturels au Moyen Age, XXXII Congrès de la SHMES (Publications de la Sorbonne: Histoire: ancienne et médiévale 70, Paris 2002) 41-70.

43 Gerd Althoff, Spielregeln der Politik im Mittelalter. Kommunikation in Friede und Fehde (Darmstadt 1997) 285.

44 Grundlegend zum Konsens als politische Kategorie im Frankenreich: Jürgen Hannig, Consensus fidelium. Frühfeudale Interpretationen des Verhältnisses von Königtum und Adel am Beispiel des Frankenreiches (Monographien zur Geschichte des Mittelalters 27, Stuttgart 1982); siehe auch Bernd Schneidmüller, Konsensuale Herrschaft. Ein Essay über Formen und Konzepte politischer Ordnung im Mittelalter, in: Reich, Regionen und Europa in Mittelalter und Neuzeit, Festschrift für Peter 
hat ersterer Tradition; in England wurde eher, wie schon bei Walter Raleigh, „the order of the Commonwealth" im Zusammenwirken mit dessen „Governors" als konstitutiv für den Staat erachtet.45

Frieds Beobachtung, daß mentale Kategorien nicht nur die Wahrnehmung, sondern auch die Formung der Realität prägen, ist außerordentlich wertvoll, doch seine etwas düstere Wertung von hilflos in falsches Bewußtsein verstrickten karolingischen Herrschern und Gelehrten steht in einem unaufgelösten Spannungsverhältnis zu seiner Betonung der Rolle sozialen Wissens in der Karolingerzeit. ${ }^{46}$ Selbst der (bekanntlich umstrittene) Nachweis, daß die karolingerzeitlichen Quellen keinen abstrakten Begriff von Staat kannten, würde nicht unbedingt ausschließen, daß man sich aus implizitem Wissen danach zu richten wußte. Soziales Wissen muß nicht explizit sein, auch die „connaissance sans concept" sozialer Zusammenhänge erlaubt, wie Bourdieu gezeigt hat, erfolgreiches Handeln. ${ }^{47}$ Freilich ist gerade in der deutschen Denktradition schwer der emphatischen Bestimmung Hegels zu entkommen, der den Staat mit seiner Idee gleichsetzte und als Ausdruck lebendigen Geistes betrachtete. ${ }^{48}$ Selbst die Kritik an der Annahme eines karolingischen und/oder ottonischen Staates scheint sich daher in Deutschland oft noch an einem platonisch-hegelianischen ,Wesen' des Staates zu orientieren, dessen Existenz als widerlegt gelten kann, wenn seine ,Idee' fehlt. Zu lange hatten Arbeiten über die ,Reichsidee“ oder die „Staatsidee“ im mittelalterlichen Imperium umgekehrt daraus Argumente für dessen Staatlichkeit abgeleitet.

\section{MITTELALTERLICHER STAAT UND ,ANTHROPOLOGISCHE WENDE“}

In der neueren deutschsprachigen Mediävistik werden statt der am modernen Staat und seinen Institutionen entwickelten Kategorien und der problematischen Quellentermini auch für die Beschreibung staatlicher Strukturen zunehmend Begriffe der Ethnologie und Sozialanthropologie benutzt. Die Rezeption solcher Modelle ist, ähnlich wie in der französischen und der anglo-amerikanischen Forschung, recht eklektisch, sie reicht von Klassikern wie James Frazer, Émile Durkheim, Marcel Mauss oder Victor Turner bis zu den seit den 60er und 70er Jahren einflußreichen Ethnologen und ethnologisch arbeitenden Soziologen wie Mary Douglas, Marshall Sahlins, Roy Rappaport, Clifford Geertz oder Pierre Bourdieu. Seltener wird in der Mediävistik die jüngere anthropologische Diskussion der rezipierten Modelle (etwa der inzwischen vielfach modifizierten Mauss'schen Vorstellungen vom Gabentausch) beachtet. ${ }^{49}$ Ethnologische Kategorien können mit Gewinn für die Gesellschaften des ,ersten Mittelalters' nutzbar gemacht werden, etwa das polynesische Tabu, ${ }^{50}$ die ,rites

Moraw, ed. Joachim Heinig (Berlin 2000) 53-87; ders., Zwischen Gott und den Getreuen. Vier Skizzen zu den Fundamenten der mittelalterlichen Monarchie, in: Frühmittelalterliche Studien 36 (2002) 193-224. Vgl. Janet L. Nelson, Peers in the Early Middle Ages, in: Law, Laity and Solidarities. Essays in Honour of Susan Reynolds, ed. Pauline Stafford/Janet L. Nelson/Jane Martindale (Manchester 2001) 27-46.

45 Remains of Sir Walter Raleigh (London 1664) 2, zitiert nach Harding, Medieval Law 2.

46 Dazu siehe auch Johannes Fried, In den Netzen der Wissensgesellschaft. Das Beispiel des mittelalterlichen Königs- und Fürstenhofes, in: Wissenskulturen. Beiträge zu einem forschungsstrategischen Konzept, ed. Johannes Fried/Thomas Kailer (Berlin 2003) 141-193.

47 Pierre Bourdieu, La distinction. Critique sociale du jugement (Paris 1979) 543.

48 Georg Wilhelm Friedrich Hegel, Grundlagen der Philosophie des Rechts (Sämtliche Werke 7, Stuttgart 1928) 350; Koselleck/ Conze, Staat $47 \mathrm{f}$. Allerdings finden sich ähnliche idealistische Auffassungen in der Soziologie Émile Durkheims: Les formes élémentaires de la vie réligieuse (Paris 1911) 604: Eine Gesellschaft sei, so meinte Durkheim, vor allem durch die Idee konstituiert, die sie von sich selbst hat.

49 Barbara Rosenwein, Francia and Polynesia. Rethinking anthropological approaches, in: Negotiating the Gift. Pre-Modern Figurations of Exchange, ed. Gadi Algazi/Valentin Gröbner/Bernhard Jussen (Göttingen 2003) 361-379. Ähnlich Philippe Buc, Political ritual: medieval and modern interpretations, in: Die Aktualität des Mittelalters, ed. Hans-Werner Goetz (Bochum 2000) 255-272; ders., Rituel politique et imaginaire politique au haut Moyen Age, in: Revue Historique 305, 4 (2001) 843-883; Mayke de Jong, The foreign past. Medieval historians and cultural anthropology, in: Tijdschrift voor Geschiedenis 109 (1996) 326-342. Vgl auch Goetz, Moderne Mediävistik 262-264. Ethnologische Kritik an Mauss: Claude Lévi-Strauss, Introduction to the Work of Marcel Mauss (London 1987; frz. 1950); Annette B. Weiner, Inalienable Possessions. The Paradox of Keeping-While-Giving (Berkeley/Los Angeles/Oxford 1992); Maurice Godelier, The L'énigme du don (Paris 1996).

50 Rosenwein, Francia and Polynesia. 
de passage ${ }^{51}$ oder Bourdieus ,symbolisches Kapital ${ }^{5}{ }^{52}$ Die ,dichte Beschreibung ${ }^{53}$ von Ritualen und anderen Formen symbolischer Kommunikation durch beobachtende Ethnologen stellt für den Mediävisten, der mit ungleich kargerem Quellenmaterial auskommen muß, eine lohnende Herausforderung dar. Im vorliegenden Band versucht Régine Le Jan ein Modell afrikanischen sakralen Königtums auf die Merowinger anzuwenden. ${ }^{54}$ Vielleicht sollte allerdings die Anregung von Barbara Rosenwein stärker berücksichtigt werden, nicht so sehr pauschale Modelle zu rezipieren, sondern konkrete Gesellschaften und Phänomene zum systematischen Vergleich heranzuziehen. ${ }^{55}$ Vor allem könnte das dazu dienen, in den Worten von Mayke de Jong, „to defamiliarize the familiar“ . ${ }^{56}$ Gerade bei der historischen Erforschung des Staates haben allgemeine ethnologische, soziologische oder politikwissenschaftliche Modelle wenig Erkenntniswert. Die Versuche, frühmittelalterliche Regna in eine Typologie des ,frühen Staates ${ }^{6}$ von Japan bis zu den Azteken einzuordnen, wirken meist recht beliebig. ${ }^{57}$

Gemeinsam ist den für früh- und hochmittelalterliche Gesellschaften verwendeten anthropologischen Modellen und Begriffen, daß sie zur Beschreibung außereuropäischer, mehr oder weniger archaischer Gesellschaften entwickelt wurden: Kategorien wie Ritual, Gabentausch, Konflikt, Inszenierung, symbolische Kommunikation und öffentliche Performanz, um nur einige zu nennen, sind an Beispielen wie den polynesischen Trobriandern und den mexikanischen Tarahumaras, balinesischen Hahnenkämpfen und dem Ehrgefühl der Tuareg geschärft worden. Zugleich spiegelt sich in ihnen das moderne Interesse am Verhältnis zwischen Individualität und Gesellschaft, Privatheit und Öffentlichkeit. ${ }^{58}$ Die erfolgreichsten dieser Begriffe werden auf vielerlei Kulturen und Sachverhalte angewendet, was ihre Elastizität zuweilen beträchtlich überfordert.

Die Öffnung der Mediävistik zu einer historisch-anthropologischen Perspektive warf neue Fragen auf und schuf damit neue Forschungsspielräume. Sie verringerte die teils immer noch beträchtlichen Unterschiede des wissenschaftlichen Stils zwischen einem Teil der deutschsprachigen Mediävistik und der franko- oder anglophonen (teils werden die weiter bestehenden Unterschiede vielleicht durch ähnliche Terminologie verdeckt). Das Interesse konzentrierte sich auch in der sozialanthropologisch orientierten deutschen Mediävistik vor allem auf die Funktionsweisen von Herrschaft bei beschränkten institutionellen Möglichkeiten, vor allem in ihrem seit jeher bevorzugten Forschungsfeld: der Reichsgeschichte des 10. bis 12. Jahrhunderts. Damit unterschieden sich die Schwerpunkte wieder deutlich von denen ähnlich orientierter Forschungen etwa in Frankreich oder Italien, wo Regionalstudien, die Erforschung der Eliten oder die Frage der „mutation féodale“ mehr Aufmerksamkeit fanden als eine sozialanthropologisch akzentuierte Untersuchung der Zentralgewalten. ${ }^{59}$ In

51 Arnold van Gennep, The Rites of Passage (Chicago 1960). Zur Anwendung auf frühmittelalterliche Grabbräuche: Frans Theuws, Introduction: Rituals in transforming societies, in: Rituals of Power. From Late Antiquity to the Early Middle Ages, ed. Frans Theuws/Janet L. Nelson (The Transformation of the Roman World 8, Leiden/Boston/Köln 2000) 1-14.

52 Pierre Bourdieu, Sozialer Sinn. Kritik der theoretischen Vernunft (Frankfurt am Main 1993) 205-221; ders., Praktische Vernunft. Zur Theorie des Handelns (Frankfurt am Main 1998) 108-114.

53 Clifford Geertz, Dichte Beschreibung. Beiträge zum Verstehen kultureller Systeme (Frankfurt am Main 1987).

54 In manchem parallel, aber aus einer anderen Forschungstradition entwickelt und daher mit unterschiedlichen Akzenten: Hans-Hubert Anton et al., Sakralkönigtum, in: RGA 2. Aufl. 26 (Berlin/New York 2004) 179-320. Ein anderer Ansatz bei: Maximilian Diesenberger/Helmut Reimitz, Zwischen Vergangenheit und Zukunft. Momente des Königtums in der merowingischen Historiographie, in: Das frühmittelalterliche Königtum, ed. Franz-Reiner Erkens (RGA Erg.Bd. 49, Berlin/New York 2005) 214-269.

55 Rosenwein, Francia and Polynesia.

56 De Jong, The foreign past $328 \mathrm{f}$.

57 Siehe z. B. The Early State, ed. Henri J. M. Claessen/Peter Skalnik (Den Haag ${ }^{3} 1978$ ); Reinhard Bendix, Könige oder Volk. Machtausübung und Herrschaftsmandat, 2 Bde. (Frankfurt am Main 1980); Michael Mann, The Sources of Social Power. The Rise of Classes and Nation States, 1760-1914, 2 Bde. (Cambridge 1986); Walter G. Runciman, A Treatise on Social Theory, Bd. 2 (Cambridge 1989); mit der Kritik von Chris Wickham, Systactic structures: social theory for historians, in: Past and Present 132 (1991) 188-203.

58 Vgl. Richard Sennett, The Fall of Public Man (New York 1975).

59 Frankreich: Guy Bois, La mutation de l'an mil. Lournand, village mâconnais, de l'antiquité au féodalisme (Paris 1989, dt.: Stuttgart 1993); Dominique Barthélemy, La mutation féodale a-t-elle eu lieu?, in: Annales ESC 47 (1992) 767-777; La royauté et les élites dans l`Europe carolingienne (début IXe aux environs de 920), ed. Régine Le Jan (Villeneuve-d'Ascq 1998); Philippe Depreux, Les sociétés occidentales du milieu du VI ${ }^{\mathrm{e}}$ au fin du IX ${ }^{\mathrm{e}}$ siècle (Rennes 2002); Régine Le Jan, La société du haut 
mancher Hinsicht setzt die Erforschung von Ritualen, „Spielregeln der Politik“, symbolischer Kommunikation bei Hof oder der Pflege aristokratischer Netzwerke durch Gabentausch die Suche der verfassungsgeschichtlichen Schule der 1940er und 50er Jahre nach den ,konkreten Ordnungen ' fort, die im zwischenmenschlichen Umgang Herrschaft durchsetzen halfen. Immer noch werden an modernen Gesellschaften und Institutionen entwickelte Kategorien weitgehend gemieden. Fixierungen auf „Ämterhierarchie und Instanzenzüge“, auf „die Funktionsweisen des modernen Staates“, verstellen, das unterstreicht Gerd Althoff, „den Weg zum Verständnis der mittelalterlichen Verhältnisse “. ${ }^{60}$ Nur die Hoffnung, daß (zumal althochdeutsche) Quellenbegriffe eine direkte Erklärung bieten könnten, ist vergangen. An ihre Stelle tritt eine Begriffssprache, die aus außereuropäischen archaischen Gesellschaften allgemeine Erklärungen für soziale Interaktion und Gemeinschaftsbildung ableitet. Das Ergebnis ist ein Bild von einem archaischen Mittelalter mit geringer gesellschaftlicher Kohärenz.

Der anthropologisch orientierte Ansatz bietet Antworten an, was denn ein früh- oder hochmittelalterliches Reich zusammenhalten kann, und zwar „auf dem weiten Feld der Rituale, Gesten und Spielregeln, die in ihrer Summe ... die mittelalterliche Staatlichkeit ausmachen“. ${ }^{61}$ Bahnbrechend bei der Suche nach einem neuen Paradigma, um das Funktionieren mittelalterlicher ,Gesellschaften ohne Staat‘ zu erklären, waren Gerd Althoffs Untersuchungen über die „Spielregeln der Politik“. ${ }^{62}$ Die Spielregeln in Konflikten und politischer Willensbildung gaben der Rangordnung der Teilnehmer großes Gewicht. ${ }^{63}$ Doch konnte der Höherstehende seinen Willen nicht einfach durchsetzen. Er mußte sich dazu auf ein komplexes rituelles Szenario einlassen, dessen Ausgang oft genug vorher abgesprochen wurde, aber entscheidend vom Konsens einer dazu berechtigten Öffentlichkeit abhing.

Zentral für Althoffs Ansatz ist daher der Begriff des Rituals. ${ }^{64}$ Rituale spielten eine integrative Rolle, da in ihnen Autoritäts- und Kräfteverhältnisse Ausdruck fanden und der soziale Zusammenhalt dargestellt wurde.$^{65}$ Rituale konnten, wie Hagen Keller bemerkt hat, „,in ganz andersartigen Machtstrukturen ... zeichenhaft eine hierarchische Gesamtordnung wenigstens als Vorstellung und Ziel sichtbar" machen. ${ }^{66}$ Dabei wurde ein reichhaltiges Instrumentarium öffentlicher Performanz und politischer Kommunikation verwendet, das mit Hilfe von Gesten, Symbolen und zur Schau gestellten Emotionen die jeweilige Konstellation augenfällig machte und mit vielfältigen Formen von Ehrungen und Gabentausch die Gesellschaft zusammenhielt. Besonders wichtig waren diese Formen ritualisierter Kommunikation bei der Konfliktbewältigung. Nicht nur, wie die ältere rechtshistorische Forschung meinte, formaler Rechtsgang, schriftliche Normen und königliche Autorität sorgten für die Eindämmung gewaltsamer Auseinandersetzungen, sondern vor allem die Befolgung ungeschriebener

Moyen Age. VI $-\mathrm{IX}^{\mathrm{e}}$ siècle (Paris 2003). Italien: Giovanni Tabacco, Egemonie sociali e strutture del potere nel medioevo italiano (Turin 1979); ders., La dissoluzione; Paolo Cammarosano, Nobili e re. L'Italia politica dell'Alto Medioevo (Turin 1998); Mineo, Di alcuni usi della nobilità medievale.

60 Althoff, Spielregeln 14.

61 Gerd Althoff, Verwandte, Freunde und Getreue. Zum politischen Stellenwert der Gruppenbindungen im frühen Mittelalter (Darmstadt 1990) 226. Eine neue Formulierung dieses programmatischen Ansatzes stammt aus: ders., Die Kultur der Zeichen und Symbole, in: Frühmittelalterliche Studien 36 (2002) 1-17, hier 16, nämlich „daß man mittelalterliche Herrschaft insgesamt - und nicht nur sie - zeichen- und ritualgeschichtlich betrachten kann und sollte, weil man so eine für das Mittelalter zentrale Perspektive einnimmt".

62 Althoff, Spielregeln. Siehe auch ders., Verwandte, Freunde und Getreue; ders., Inszenierte Herrschaft. Geschichtsschreibung und politisches Handeln im Mittelalter (Darmstadt 2003); ders., Die Macht der Rituale. Symbolik und Herrschaft im Mittelalter (Darmstadt 2003).

${ }^{63}$ Heinrich Fichtenau, Lebensordnungen des 10. Jahrhunderts. Studien zu Denkart und Existenz im einstigen Karolingerreich (Stuttgart 1984); Brunner, Land und Herrschaft; Althoff, Inszenierte Herrschaft $276 \mathrm{f}$.

64 Zusammenfassend Althoff, Spielregeln 1-17; 282-304, ders., Macht der Rituale.

65 Geoffrey Koziol, Begging Pardon and Favor. Ritual and Political Order in Early Medieval France (Ithaca/London 1992); Rituals of Power. From Late Antiquity to the Early Middle Ages, ed. Frans Theuws/Janet L. Nelson (The Transformation of the Roman World 8, Leiden/Boston/Köln 2000); Hagen Keller, Ritual, Symbolik und Visualisierung in der Kultur des ottonischen Reiches, in: Frühmittelalterliche Studien 35 (2001) 23-59; Althoff, Macht der Rituale.

66 Keller, Investitur 77. 
Spielregeln durch die Konfliktparteien, die eine gewisse Erwartungssicherheit schuf, sowie informelle Vermittlungsverfahren in allen Stadien eines Konflikts und ritualisierte Versöhnung am Ende. ${ }^{67}$ Gegenüber dem älteren Modell der Fehde, das eher die unerbittliche Logik der Rache hervorhob, bietet der offenere Konfliktbegriff wesentliche Vorteile. ${ }^{68}$ Die flexiblen Kategorien Konfliktbewältigung, Performanz und symbolische Kommunikation sind bei diesem Ansatz eingebettet in den formal strukturierenden Begriff der Spielregeln; den Schlüssel zu diesem Modell politischer Integration bildet das Ritual, dem strategische Erklärungsmacht aufgebürdet wird.

Der Ritualbegriff hat nicht nur in der Mediävistik in den letzten Jahrzehnten großen Erfolg gehabt. Popularisiert wurde er vor allem durch die grundlegenden religionssoziologischen Studien von Émile Durkheim am Beginn des 20. Jahrhunderts: Hinter den Erscheinungen, den vielfältigen Glaubensinhalten und zeremoniellen Formen, suchte er die Funktion und abstrahierte daher aus ihnen ein relativ zeitresistentes ,kollektives Bewußtsein', das sich in rituellen ,kollektiven Repräsentationen“ ausdrückt und dadurch die Gesellschaft zusammenhält. ${ }^{69}$ Getreu der Methode Durkheims wurde zunächst hinter der Erscheinung das Wesen gesucht, nämlich die integrative Funktion des Rituals. ${ }^{70}$ Die Forschung konzentrierte sich daher auf soziale Zusammenhänge, die sich über die Köpfe der Teilnehmer hinweg herstellen: Fast sprach- und gedankenlose, streng formalisierte Rituale, in deren Korsett sich eine weitgehend archaische Gesellschaft selbst abbildet und durch die sie eher zur Wahrnehmung ihrer selbst als zu einer Vorstellung von sich selbst findet. Der Reiz ethnologischer Begriffe wie ,Ritu-

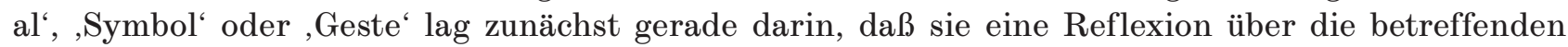
Handlungen oder Objekte auszuschließen schienen; so betrachtet, steht dahinter eine irrationalistische Gesellschaftstheorie, wie sie in der Mitte des 20. Jahrhunderts große Faszinationskraft entwikkelte. Sicherlich muß ,Ritual ' Reflexion nicht unbedingt ausschließen, der Begriff wird aber oft im Sinn eines im wesentlichen unreflektierten Vorganges verstanden. ${ }^{71}$

Im letzten Drittel des 20. Jahrhunderts hat sich die Ritualforschung differenziert und den Begriff von unterschiedlichen Seiten her kritisch hinterfragt. Einflußreich war etwa das Werk von Clifford Geertz; er geht von einem semiotischen Ansatz aus, um fremde Kulturen und ihre „sozialen Diskurse“ gleichsam wie Texte zu "lesen“ und dabei nicht nur die wahrnehmbaren Vorgänge zu beschreiben, sondern zugleich ihren Zeichencharakter zu enthüllen. ${ }^{72}$ Die Fragestellung, wie (und nicht nur was) Rituale bedeuten, überbrückte das Spannungsfeld zwischen Handlung und beschreibendem Text und öffnete den Begriff für eine Vielzahl von Anwendungen, die weit über den ursprünglichen Ansatz Durkheims hinausgingen. Heute gehört Ritual, ähnlich wie Kommunikation, Symbol, Identität, zu jenen Kategorien, die im gesamten Bereich der Kultur- und Sozialwissenschaften von Nutzen sind und zugleich den einzelnen Fächern reichen interdisziplinären Mehrwert versprechen. Daß sie durch die Verwendung in ganz unterschiedlichen Disziplinen und Methodengebäuden ziemlich diffus werden,

67 The Settlement of Disputes in Early Medieval Europe, ed. Wendy Davies/Paul Fouracre (Cambridge 1986); Patrick J. Geary, Vivre en conflit dans une France sans état: Typologie de mécanisme de règlement des conflits (1050-1200), in: Annales ESC 41 (1986) 1107-1133; Walter Pohl, Konfliktverlauf und Konfliktbewältigung: Römer und Barbaren im frühen Mittelalter, in: Frühmittelalterliche Studien 26 (1992) 165-207; Althoff, Macht der Rituale 68-84; Conflict in Medieval Europe. Changing Perspectives on Society and Culture, ed. Warren C. Brown/Piotr Górecki (Aldershot/Burlington, Vermont 2003), besonders der einleitende Forschungsüberblick der Herausgeber, What conflict means: the making of conflict studies in the United States, 1970-2000, 1-36.

68 Kritisch gegenüber einer Verallgemeinerung des Fehdebegriffes: Guy Halsall, Reflections on early medieval violence: the example of the ,blood feud', in: Memoria y Civilización 2 (1999) 7-29; ders., Violence and society in the early medieval west: an introductory survey, in: Violence and Society in the Early Medieval West, ed. ders. (Woodbridge 1998) 1-45.

${ }^{69}$ Durkheim, Les formes élémentaires. Vgl. Philippe Buc, The Dangers of Ritual. Between Early Medieval Texts and Social Scientific Theory (Princeton 2001) 223-227.

70 Buc, Political ritual, zur Kritik dieses funktionalistischen Ansatzes.

71 Niklas Luhmann, Soziale Systeme. Grundriß einer allgemeinen Theorie (Frankfurt am Main 1984) 613, begreift, Ritual` als fixierten Ablauf, der alle „Ansätze für reflexive Kommunikation“ coupiert; anders Althoff, Macht der Rituale 12f., der darin nur den Sonderfall der ,leeren“ oder ,starren‘ Rituale sieht.

72 Geertz, Dichte Beschreibung $11 \mathrm{f}$. Zur Stellung von Geertz in den Kulturwissenschaften siehe Andreas Reckwitz, Die Transformation der Kulturtheorien. Zur Entwicklung eines Theorieprogramms (Weilerswist 2000) 445-477. 
spricht nicht gegen ihren Gebrauch, will aber reflektiert sein. ${ }^{73}$ Rituale werden als Kommunikation und Performanz, religiöser Akt und Medium der Herrschaftsrepräsentation, als Sinn- und Identitätsstiftung, Machtdurchsetzung oder Konfliktlösung, Affirmation oder Transformation, als psychisches Symptom oder stereotype Handlung im Alltag und vieles andere untersucht.

Selbst wo eine sehr überzeugende engere Definition versucht wird, muß der Autor anschließend feststellen, daß sogar eine Blinddarmoperation den meisten seiner Kriterien entspricht. ${ }^{74}$ Catherine Bell hat deshalb vorgeschlagen, statt dem starren Ritual-Begriff von Ritualisierung oder ritualisiertem Handeln zu sprechen und damit eine Tendenz, eine unterschiedlich stark ausgeprägte Handlungsebene zu beschreiben. Ihrer Ansicht nach liegt der Ritualforschung eine Art Zirkelschluß zugrunde: Zuerst wird das Ritual als Handlung vom Denken (also von Vorstellungen, Mythen und Symbolen) unterschieden, um dann als jener Bereich hervorgehoben zu werden, wo sich Handeln und Denken versöhnen. ${ }^{75}$ Ihre methodische Schlußfolgerung ist bedenkenswert: Rituale sollten weniger im $\mathrm{Zu}-$ sammenhang mit anderen Ritualen untersucht werden, zumal ein universeller, transkultureller Ritualbegriff fast inhaltsleer wäre, sondern im Kontext anderer sozialer und kultureller Praktiken, also innerhalb des spezifischen gesellschaftlichen Umfeldes. ${ }^{76}$ Das entspricht der Aufgabe der Geschichtswissenschaft, den Ritualbegriff möglichst zu historisieren.

Die meisten Autoren gehen weiterhin davon aus, daß „das Ritual als kulturelle Performance einen privilegierten Blick in das Innere einer Kultur bietet. "77 Freilich beschreibt der Ritualbegriff keine klar abgrenzbare Menge objektiv gegebener Ereignisse - auch die untersuchten Gesellschaften selbst hatten dafür keinen einheitlichen Begriff -, sondern ein heuristisches Instrument, das bestimmte Handlungsweisen und soziale Zusammenhänge nach (oft sehr unterschiedlichen) modernen analytischen Kriterien aus einem kulturellen Kontinuum herauslöst. ${ }^{78}$ Die ,anthropologische Wende der Mediävistik wirft also, so wertvoll ihre Ergebnisse sind, einige schwierige methodische Fragen auf. Welche anthropologischen Theorien und Modelle werden durch eine recht eklektische Rezeption in der Mediävistik gemeinsam mit den verwendeten Kategorien eigentlich übernommen? Kann politische Integration durch anthropologische Kategorien wie Ritual, symbolische Kommunikation und Konfliktbewältigung zureichend erklärt werden? Bevor alle diese Begriffe als erklärungsmächtige Kürzel in die Handbücher eingehen, sollten ihre Möglichkeiten und Grenzen in der Mittelalterforschung eingehender diskutiert werden. Philippe Buc hat in seinem Buch über „The Dangers of Ritual“ die Kritik am Ritualbegriff aufgenommen und gefordert, „the reductionist, too-often vague, and essentially

73 Eine gute Übersicht bieten die beiden Sammlungen grundlegender Arbeiten: Ritualtheorien. Ein einführendes Handbuch, ed. Andréa Belliger/David J. Krieger (Opladen/Wiesbaden 1998); siehe besonders die Einführung der Herausgeber (7-32); sowie Rituale heute. Theorien - Kontroversen - Entwürfe, ed. Corina Caduff/Joanna Pfaff-Czarnecka (Berlin 1999). Grundlegend zur Kritik der Ritualtheorie: Catherine Bell, Ritual Theory - Ritual Practice (New York/Oxford 1992); immer wieder zitiert wird auch die kritische Skizze von Jack Goody, Against ritual: ,Loosely structured thoughts on a loosely defined topic', in: Secular Ritual, ed. Sally Falk Moore/Barbara G. Myerhoff (Assen/Amsterdam 1977) 25-35. Ein großer Entwurf der Ritualtheorie: Roy A. Rappaport, Ritual and Religion in the Making of Humanity (Cambridge 1999). Siehe auch: Gunter Gebauer/Christoph Wulf, Spiel - Ritual - Geste. Mimetisches Handeln in der sozialen Welt (Reinbek 1998); Theorizing Rituals. Classical Topics, Theoretical Approaches, Analytical Concepts, ed. Jens Kreinath/Jan Snoek/Michael Stausberg (Leiden 2004); Ritualdynamik. Kulturübergreifende Studien zur Theorie und Geschichte rituellen Handelns, ed. Dietrich Harth/Gerrit Jasper Schenk (Heidelberg 2004); Die Welt der Rituale. Von der Antike bis heute, ed. Claus Ambus/Stephan Hotz/Gerald Schwedler/Stefan Weinfurter (Darmstadt 2005).

74 Axel Michaels, ,Le rituel pour le rituel‘ oder wie sinnlos sind Rituale?, in: Rituale heute, ed. Caduff/Pfaff-Czarnecka, 23-47, bes. 39; siehe ebd. 29 zu seiner fünfteiligen Definition des Rituals. Gebräuchlich und recht detailliert ist auch die Ritual-Definition von Stanley J. Tambiah, Eine performative Theorie des Rituals, in: Ritualtheorien, ed. Belliger/Krieger, 227-250, bes. 231 .

75 Bell, Ritual Theory, bes. 88-93; 19-21.

76 Bell, Ritual Theory 90.

77 Belliger/Krieger, Einleitung 27.

78 Tambiah, Eine performative Theorie des Rituals 227, betont, daß es „unmöglich ist, mit Absolutheit ziwschen Ritual und Nicht-Ritual zu unterscheiden“. Axel Michaels, Inflation der Rituale? Grenzen eines vieldeutigen Begriffs, in: humanismus aktuell 13 (2003) 25-36, hier 34: „Es gibt nicht das Ritual, losgelöst von allen historischen, regionalen oder sprachlichen Kontexten. Es gibt nicht das Wesen des Rituals.“ 
alien concept of ,ritual “ zu meiden. Sein Buch hat allerdings manche nach seinen früheren Veröffentlichungen hochgesteckte Erwartungen enttäuscht. ${ }^{79}$

Der Ritualbegriff beschreibt, wie Buc richtig festgestellt hat, Handlungen, die der Mittelalterforschung nur über Texte zugänglich sind. Damit überlagern sich zwei verschiedene Ebenen der Bedeutungsproduktion, was die Aufgabe ihrer Deutung erschwert. Umso wichtiger ist es, den Begriff und seine Grenzen zu reflektieren.

Unter anderem stellt sich die grundlegende Frage, ob darunter nur religiöse Handlungen zu verstehen sind, wie es dem Modell von Durkheim entspricht. Diesen Gesichtspunkt hat zuletzt vor allem Axel Michaels hervorgehoben; in seiner Definition ist „Transzendenz“ als „modales Handlungskriterium“ eine der fünf Komponenten von Ritualen. ${ }^{80} \mathrm{Er}$ faßt zusammen: „Rituale haben die Bedeutung, bedeutungslos zu sein, weil so Zeitlosigkeit, Unveränderlichkeit, Unsterblichkeit - eben religio - für sterbliche Menschen in Szene gesetzt werden kann." ${ }^{81}$ Andere Schattierungen des Begriffs greifen weit auf weltliche, ja alltägliche Handlungssequenzen aus. ${ }^{82}$ Dieses Abgrenzungsproblem trifft die Mittelalterforschung weniger als andere Disziplinen, da auch Rituale weltlicher Macht in der Regel einen transzendentalen Bezug hatten; sie hoben meist gerade die Unveränderlichkeit des Reiches und seine christliche Legitimität in den wechselnden Machtkonstellationen hervor. Deshalb empfiehlt sich in der Mittelalterforschung ein eher eng gefaßter Ritualbegriff, der nicht wie in anderen Disziplinen weitgehend säkularisiert werden muß. ${ }^{83}$

Wenn Rituale Zeitlosigkeit inszenieren, benötigen sie auch die Aura der Unveränderlichkeit. ${ }^{84}$ Daher werden sie meist als konventionell und formalisiert betrachtet, was intentionales Handeln weitgehend ausschließt. ${ }^{85}$ Konventionalität, Rigidität, Stereotypie und Repetitivität gelten in der Regel als wichtige Kriterien. ${ }^{86}$ Das kann bei mittelalterlichen Beispielen Probleme bereiten. Wenn Rituale konventionell und wiederholbar sind, wäre zum Beispiel die Kaiserkrönung Ludwigs des Frommen als einzigartiger Vorgang kein Ritual gewesen; allenfalls könnte man argumentieren, daß sie auf Wiederholbarkeit angelegt war. Freilich muß nicht unbedingt der ganze rituelle Ablauf stereotyp sein, es genügt, wenn die Elemente bekannt sind. Eine rituelle Ordnung beruht auf ihrer Verbindlichkeit und Wiedererkennbarkeit, sozusagen einer Grammatik der symbolischen Sprache, die alle Teilnehmer verstehen sollten. Rituelle Handlungen werden, folgt man der Definition von Rappaport, von den Teilnehmern nicht spontan entworfen, sondern aus einem bestehenden Inventar übernommen. ${ }^{87}$ Das scheint zunächst die Annahme ihres archaischen Charakters nahezulegen, daß nämlich die Spielregeln den politischen Akteuren quasi naturwüchsig zur Verfügung gestanden wären, in gewisser Weise aus einem urtümlichen Zeichenvorrat geschöpft, dessen sich alle archaischen Gemeinschaften bedienten. Die Rituale, die aus mittelalterlichen Quellen bekannt sind, passen oft schlecht zu einer solchen archaisch-rigiden Definition. Sie enthalten viele Beispiele dafür, daß Rituale fehlschlagen oder mißverstanden werden konnten, daß ihre Bedeutung umstritten war, daß sie verändert oder neu ge-

79 Buc, The Dangers of Ritual, bes. 247; siehe auch seine früheren Aufsätze, u. a. ders., Political ritual; ders., Le rituel politique. Siehe u. a. die kritischen Rezensionen von Janet Nelson, in: Speculum 78 (2003) 847-850; und Geoffrey Koziol, The dangers of polemic: Is ritual still an interesting topic of historical study?, in: Early Medieval Europe 11 (2002) 367-388.

80 Michaels, ,Le rituel pour le rituel` 29.

81 Michaels, ,Le rituel pour le rituel' 45 . Tambiah, Eine performative Theorie des Rituals 230-232, erweitert den religiösen Inhaltsbereich des Rituals auf den kosmologischen: ,jene orientierenden Prinzipien und Begriffe, die als heilig betrachtet, ständig als Maßstäbe benutzt und wegen ihrer Würde ohne große Änderung beibehalten werden." Diese Maßstäbe können auch politische Konventionen umfassen.

82 Siehe z. B. Secular Ritual, ed. Falk Moore/Myerhoff.

83 Zur Frage des Begriffsumfangs siehe auch Koziol, Begging Pardon and Favor 289. Timothy Reuter, Velle sibi fieri in forma hac: Symbolisches Handeln im Becketstreit, in: Formen und Funktionen öffentlicher Kommunikation im Mittelalter, ed. Gerd Althoff (Sigmaringen 2001) 201-226, hier 203, schlägt vor, zwischen dem Stabilität und Konformität erfordernden Ritual und dem weiteren Begriff der symbolischen Kommunikation zu unterscheiden.

84 Michaels, ,Le rituel pour le rituel` 44.

85 Tambiah, Eine performative Theorie des Rituals 236.

86 Tambiah, Eine performative Theorie des Rituals 233-235.

87 Rappaport, Ritual and Religion 24 und 36: „encoding by others than the performers“ als Definitionsmerkmal des Rituals. 
deutet wurden. ${ }^{88}$ Daher hat Althoff nun Gemachtheit und Geschichtlichkeit der Rituale hervorgehoben. ${ }^{89}$ Jede rituelle Interaktion beeinflußte die Spielräume folgender Interaktionen, sie wurden diskutiert, erprobt, und verändert, bei Hof und anderswo.

Schwierigkeiten macht auch die Frage, ob Rituale notwendigerweise eine Transformation bedeuten. Victor Turner definiert Ritual als „transformative performance“, Michaels sieht ebenfalls das „Kriterium der Transitionalität“ als grundlegend an. ${ }^{90}$ Dann wären eine Königskrönung oder ein Herrscherbegräbnis Rituale, nicht aber der Empfang von Gesandten, Gastmähler, Festkrönungen oder regelmäßige Reichsversammlungen. Wieder, wie bei der Frage der Transzendenz von Ritualen, geht es um ein grundlegendes Abgrenzungsproblem. Herrschaftsrepräsentation, die sich ritueller Formen bedient, entfernt sich damit von jenen existenziellen Ritualen, mit denen eine Gesellschaft sich ihrer selbst vergewissert, Transzendenz schafft und ihre Lebensrhythmen skandiert. Bedient sich die Macht des Rituals, eröffnet sie damit zugleich ein Spannungsfeld zwischen der primordialen Aura und der Gemachtheit der Rituale. Die Rituale sind dann nicht mehr rein typologisch oder gar in ihrem Wesen zu erfassen, sondern, entsprechend der methodischen Forderung von Catherine Bell, nur mehr in ihrem sozialen Umfeld historisch zu interpretieren.

Das erklärt vielleicht den Erfolg derjenigen Ansätze, die das Element der Performanz in Ritualen betonen. Clifford Geertz studierte in Bali die einzigartige Dramaturgie, durch die weite Lebensbereiche quasi als Schauspiel stilisiert wurden; den gesellschaftlichen Zusammenhalt fand er in den allgemeingültigen und zeitresistenten sozialen Rollen der Akteure begründet. Das Theater der Macht repräsentiert daher nicht, sondern ,präsentiert', es macht gegenwärtig. „Mass ritual was not a device to shore up the state, but rather the state ... was a device for the enactment of mass ritual. "91 Für die Untersuchung ottonischer Herrschafts/re/präsentation erwies sich dieses Vergleichsbeispiel als sehr anregend. ${ }^{92}$ Der Inszenierung von Herrschaft schenkten schon Zeitgenossen große Aufmerksamkeit. Freilich, die Verknüpfung der Ritualforschung mit neueren Ansätzen der Performanztheorie ist nicht unproblematisch. ${ }^{93}$ Die Metapher des Theaters unterläuft gerade das Element der Verbindlichkeit des Rituals, denn Inszenierung erlaubt Manipulation, Performanz legt Variierung und Distanzierung nahe. ${ }^{94}$ Solche Formen der „Präsentation“ setzen Reflexion voraus und erfordern letztlich eine Unterscheidung zwischen Inszenierung und Performanz, zwischen Akteuren und Publikum. Wer die Akteure sind und welche sozialen Rollen sie im Ritual (oder der Performanz?) verkörpern, entscheidet sich daher nicht erst durch das Ritual, sondern bereits in seinem Vorfeld, auch wenn es im Ritual selbst bewährt werden muß. Vor allem geht es dabei um die diffizile Ordnung der Ehre, deren gegenseitige öffentliche Zuerkennung spezialisiertes Wissen über Rangordnungen und ihren Ausdruck erfordert. ${ }^{95}$ Rituelle Kommunikation muß also, teils in sekundärer Sozialisation, er-

88 Buc, Political ritual.

89 Althoff, Macht der Rituale, bes. 189-198.

90 Victor Turner, The Ritual Process. Structure and Anti-Structure (London 1969); ders., The Anthropology of Performance (New York 1987); Michaels, ,Le rituel pour le rituel‘ 30.

91 Clifford Geertz, Negara: The Theatre-State in Nineteenth-Century Bali (Princeton 1980). Zusammenfassung: ders., Dichte Beschreibung 297-301. Kritisch dazu: Buc, The Dangers of Ritual 227-230.

92 Timothy Reuter, Regemque, quem in Francia pene perdidit, in patria magnifice recepit: Ottonian ruler-representation in synchronic and diachronic comparison, in: Herrschaftsrepräsentation im ottonischen Sachsen, ed. Gerd Althoff/Ernst Schubert (Vorträge und Forschungen 46, Sigmaringen 1998) 366-380; Keller, Investitur.

93 Grundlegend: Turner, The Anthropology of Performance; Richard Schechner, Performance Theory (New York/London 1988). Mediävistische Anwendungen z. B.: Performance and Transformation. New Approaches to Late Medieval Spirituality, ed. Mary Suydam/Joanna Ziegler (New York 1999).

94 Tambiah, Eine performative Theorie des Rituals, bes. 244. Siehe die fundierte Kritik an der unbekümmerten Verbindung von ,Ritual' und ,Inszenierung' bei Christina Pössel, Symbolic communication and the negotiation of power at Carolingian regnal assemblies, 814-840 (PhD Cambridge 2003) mit dem Kapitel über: Conceptualising early medieval symbolic communication. Ähnliche Einwände bei Jean-Marie Moeglin, Rituels et, Verfassungsgeschichte“ au Moyen Age. A propos du livre de Gerd Althoff, Spielregeln der Politik im Mittelalter, in: Francia 25 (1998) 245-250, hier 248, der eine Unterscheidung zwischen rein demonstrativen und illustrativen Zeremonien und jenen performativen Ritualen vermißt, die verpflichten („gestes qui obligent").

95 Pössel, Symbolic Communication, mit dem Kapitel: Conceptualising early medieval symbolic communication. 
lernt werden. Sie ist kein Merkmal des Archaischen, der politischen Macht- und Sprachlosigkeit, sondern ein komplexes kulturelles Konstrukt. ${ }^{96}$ Sie ist auch keineswegs vorwiegend nonverbal, wie Rappaport betont. ${ }^{97}$

Die Inszenierung des Herrschers und seiner Begegnung mit den Großen des Reiches erreichte ihren Höhepunkt im höfischen Absolutismus. ${ }^{98}$ Hier, vielleicht naheliegender als in der außereuropäischen Ethnologie, sind Vergleichsbeispiele für mittelalterliche Rituale der Macht zu finden. Die un-

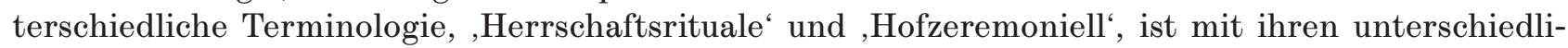
chen Obertönen - beim einen dunkle archaische Verbindlichkeit, beim anderen ästhetische Raffinesse - ein wenig irreführend. Streit um die richtige Rangordnung war am barocken Habsburgerhof ebenso wohlbekannt wie an dem der Ottonen, und auch auf rituelle Selbsterniedrigung verstanden sich die Habsburgerkaiser bestens, etwa im jüngst breit untersuchten Zeremoniell der Fußwaschung. ${ }^{99}$ Das byzantinische Hofzeremoniell könnte ebenfalls zum Vergleich herangezogen werden. ${ }^{100}$ Die These Althoffs, „dass sich das kulturelle Niveau ritueller Ausdrucksformen, wie es im Hochmittelalter bestand, einem Lernprozeß verdankt, den man in der Karolinger- und Ottonenzeit beobachten kann“, ist zwar durchaus einleuchtend. ${ }^{101}$ Doch unterschätzt sie wohl die vielfältigen rituellen und symbolischen Formen, die das Merowingerreich vom Imperium Romanum, dem Byzantinischen Reich und vom Christentum übernommen hatte. ${ }^{102}$ Die eher kargen Informationen karolingerzeitlicher Autoren über symbolische Kommunikation könnten Ausdruck ihrer spezifischen Interessen sein und müssen nicht den tatsächlichen Stand der Ritualisierung spiegeln. ${ }^{103}$ Vielleicht sollte man die Vorstellung von einer linearen Entwicklung doch differenzieren und die je spezifischen Voraussetzungen stärker in den Blick nehmen. ${ }^{104}$

Ohne die reiche Zeichensprache christlichen ,Rituals“ wäre die rituelle Selbstdarstellung hochmittelalterlicher Herrscher undenkbar, man denke nur an die Selbstdemütigung oder exaltatio ${ }^{105}$ Christliche Liturgie war den Ritualen am Hof der Karolinger oder Ottonen auch nicht äußerlich, sondern ihr integraler Bestandteil. Nicht alle kirchlichen Rituale waren liturgisch, und nicht alle Liturgie war direkt aus ,der' Schrift geschöpft, dennoch waren sie im Früh- und Hochmittelalter in ein dichtes Netz der Schriftlichkeit verwoben. Liturgische Handschriften legten minutiös ,rituelle‘ Abläufe fest und erörterten ihre vielfältigen symbolischen Bedeutungen - reichhaltige und oft vernachlässigte Bei-

96 Das hebt auch Keller, Ritual, Symbolik und Visualisierung, hervor. Siehe Gerd Althoff, Herrschaftsausübung durch symbolisches Handeln oder: Möglichkeiten und Grenzen der Kommunikation mittels Zeichen, in: Comunicare e significare nell'Alto Medioevo (Settimane di studio del centro italiano di studi sull'alto medioevo 52, Bd. 1, Spoleto 2005) 367-394.

97 Rappaport, Ritual and Religion 29: „In human ritual the utterances are usually predominantly verbal“.

98 Zeremoniell und Raum, ed. Werner Paravicini (Residenzforschung 6, Sigmaringen 1997), mit der programmatischen Einleitung des Herausgebers (1-27).

99 Martin Scheutz, Der vermenschte Heiland. Der Herrscher in der Nachfolge Christi. Die Armenspeisung und die Gründonnerstags-Fußwaschung am Wiener Kaiserhof, in: Der geteilte Ort. Kaiserhof und Stadt in der Neuzeit, ed. Susanne Pils/Jan Paul Niederkorn (Wien 2005) 177-241.

100 Otto Treitinger, Die oströmische Kaiser- und Reichsidee nach ihrer Gestaltung im höfischen Zeremoniell (Jena 1938, ND Darmstadt 1956); Michael McCormick, Analyzing imperial ceremonies, in: Jahrbuch der österreichischen Byzantinistik 35 (1985) 1-20; ders., De Cerimoniis, in: The Oxford Dictionary of Byzantium 1 (New York/Oxford 1991) 595-597; Averil Cameron, The construction of court ritual: the Byzantine Book of Ceremonies, in: Rituals of Royalty: Power and Ceremonial in Transitional Societies, ed. David Cannadine/Simon Price (Cambridge 1987) 106-36; Gilbert Dagron, Emperor and Priest. The Imperial Office in Byzantium (Cambridge 2003), bes. 84-124.

101 Althoff, Macht der Rituale 195.

102 Michael McCormick, Eternal Victory. Triumphal Rulership in Late Antiquity, Byzantium and the Early Medieval West (Cambridge 1986); ders., Clovis at Tours, Byzantine public ritual and the origins of medieval ruler symbolism, in: Das Reich und die Barbaren, ed. Evangelos Chrysos/Andreas Schwarcz (Veröffentlichungen des Instituts für Österreichische Geschichtsforschung 29, Köln/Wien 1989) 155-180; Joachim Ehlers, Grundlagen der europäischen Monarchie in Spätantike und Mittelalter, in: Majestas 8/9 (2000/01) 49-80; Frank Kolb, Herrscherideologie in der Spätantike (Berlin 2001).

103 Pössel, Symbolic communication, mit dem Kapitel: Conceptualising early medieval symbolic communication.

104 Siehe etwa Janet L. Nelson, The Lord's anointed and the peoples' choice: Carolingian royal ritual, in: dies., The Frankish World 750-900 (London/Rio Grande 1996) 99-132, bes. $131 \mathrm{f}$.

105 Althoff, Macht der Rituale, bes. 106 ff., der die christlichen Einflüsse ebenfalls hervorstreicht; Keller, Ritual, Symbolik und Visualisierung, bes. 25 . 
spiele mittelalterlicher Sinnproduktion. ${ }^{106}$ Für die Rituale am Königshof sind ähnliche detaillierte Anleitungen weniger erhalten, sieht man von Krönungsordines und ähnlichem ab. ${ }^{107}$ Das mag unter anderem damit zusammenhängen, daß sie verhandelbar, teils auch ambivalent bleiben mußten. Auch ließ man wohl manche Unterwerfungs- und Demutsgesten besser unerklärt, sonst wäre die Schwelle dazu noch höher gewesen. Daß die Unterwerfung eines weltlichen Herrn sich der Formen einer Demutsgeste gegenüber Christus bediente, entsprach nicht nur christlichen Herrschaftskonzeptionen, sondern machte sie wohl auch leichter zu ertragen. ${ }^{108}$ Erst der Bedeutungsüberschuß, den der betreffende christliche Diskurs produzierte, machte viele Rituale der Macht verständlich. Sie sind daher nicht einfach losgelöst davon als eigenständiger Bereich mündlichen weltlichen Rituals neben dem verschriftlichten christlichen Ritus zu betrachten.

All das bedeutet, daß im Mittelalter Rituale und symbolische Kommunikation nicht analog zu schriftlosen Gesellschaften gesehen werden können. ${ }^{109}$ Schriftliche und symbolische Ausdrucksformen verweisen ständig aufeinander. ${ }^{110}$ Eine Urkunde oder Handschrift wird feierlich überreicht, es wird unter Beachtung zeremonieller Formen daraus vorgelesen, in rituell festgelegter Wechselrede darüber verhandelt, über das Ergebnis wird Protokoll geführt und später eventuell ein allen formalen Standards gerechtes (eignet sich dafür noch das Attribut ,rituell‘?) feierliches Privileg ausgefertigt. ${ }^{111}$ Vielleicht wird der Vorgang später sogar in einer historiographischen Quelle erwähnt, sicherlich aber vielfach erinnert und erzählt oder bei einfacheren Urkundenausstellungen mimetisch nachgeahmt. Das Ritual ist nur ein Ausschnitt dieses komplexen Vorganges. Ebenso wie die Rechtssprache und das Schreiben ist es eine Kulturtechnik (ein „kulturell konstruiertes System symbolischer Kommunikation “, nach der Definition von Stanley Tambiah ${ }^{112}$ ), die politisches Handeln und Verhandeln ermöglicht, aber nicht selbst Hauptzweck und Inhalt politischer Integration.

In diesem Zusammenhang steht auch die Schilderung von Ritualen in schriftlichen Quellen, die unseren einzigen Zugang zur rituellen Kommunikation des Mittelalters darstellt. Dort finden wir sie jeweils eingebettet in politische Verhandlungen, Machtkämpfe, Bündnisse und andere Konstellationen ,staatlichen' Handelns. Richtiges und falsches politisches Verhalten ist ein Hauptanliegen unzähliger schriftlicher Texte, von Historiographie und Hagiographie über Kapitularien und Briefe bis zu Fürstenspiegeln und exegetischen Traktaten. Das Bild einer letztlich schriftlosen und unreflektierten Zeit, die ihre politischen Handlungen aus der Verbindlichkeit archaischer Rituale und/oder christlicher moralischer Gemeinplätze ableitete, paßt schlecht zur Kritikfreude und Vielstimmigkeit dieser Quellen. Frühmittelalterliche Versammlungen waren nur zum Teil Szenarien vorher feststehender oder festgelegter symbolischer Kommunikation. Karolingische Kapitularien zum Beispiel mögen in unterschiedlichem und oft nur bescheidenem Maß vermocht haben, soziale Realität zu verändern. Doch sind sie Ergebnisse eines politischen Prozesses, dessen Horizont das Regnum, die Ecclesia, später auch das Imperium war. Gemeint, teils auch betroffen war eine Gemeinschaft, die nicht bloß diejenige der Teilnehmer an den jeweiligen Versammlungen war, sondern letztlich alle Menschen, die auf einem Territorium von hunderttausenden Quadratkilometern lebten.

106 Siehe z. B. Arnold Angenendt, Liturgik und Historik (Freiburg 2001); Meta Niederkorn-Bruck, Liturgische Texte als Quellen zur Frühgeschichte des Erzbistums Salzburg (MIÖG Erg.Bd., im Druck).

107 Siehe allerdings Staubach, Signa utilia 38: „Eine dichte Texttradition, die von Augustinus und der Bendediktsregel über Gregor d. Gr. und Isidor bis zu den insularen und karolingischen Fürstenspiegeln und Konzilskanones reicht, dokumentiert die Entfaltung des christlichen Amtsgedankens und seine durch strukturelle Analogien erleichterte Übertragung vom Bischof und Abt auf den König."

108 Vgl. den Beitrag vom Matthias Becher, in diesem Band.

109 „Eine Gesellschaft, die Verhalten so normiert und ritualisiert wie die mittelalterliche, kann auch ohne Schriftlichkeit Stabilität erzeugen“ - Althoff, Spielregeln 290. Siehe aber Keller, Ritual, Symbolik und Visualisierung 57: „Die komplexe Ritualsprache des Hochmittelalters ist nur in der Rückkoppelung an Inhalte und Normen der schriftkuturellen Tradition voll verständlich“.

110 Arnold Angenendt, Cartam offerre super altare, in: Frühmittelalterliche Studien 36 (2002) 133-158.

111 Zur Interaktion von Schrift und Performanz siehe u. a. Peter von Moos, Zwischen Schriftlichkeit und Mündlichkeit: Dialogische Interaktion im lateinischen Hochmittelalter, in: Frühmittelalterliche Studien 25 (1991) 300-314; Patrick J. Geary, Land, language and memory in Europe, 700-1100, in: Transactions of the Royal Historical Society, $6^{\text {th }}$ series, 9 (1999) $169-184$.

112 Tambiah, Eine performative Theorie des Rituals 230. 
Hier besteht ein weiteres methodisches Problem: Die ethnographischen Vergleichsbeispiele beziehen sich zumeist auf face-to-face-Gemeinschaften oder zumindest regional sehr begrenzte Gemeinwesen. Das karolingische oder das ottonische Imperium stellten einen viel weiträumigeren Zusammenhang her. Sie wurden (ähnlich wie das Imperium Romanum) zusammengehalten von einer Gruppe von wenigen Hunderten bis Tausenden Menschen, die zur Teilnahme an den politischen Entscheidungen berechtigt und fähig waren. Diese lassen sich weitgehend als face-to-face group beschreiben, kannten einander mehr oder weniger von den wiederholten Aufenthalten bei Hof oder von Heerzügen und waren in vielfältigen Netzwerken untereinander verbunden (siehe den Beitrag von Stuart Airlie in diesem Band). Andererseits war ihr persönlicher Kontakt nicht vorgegeben wie in einer ,archaischen“ Gemeinschaft, sondern mußte unter größten Anstrengungen aufrechterhalten werden. Mitglieder regionaler Eliten begaben sich an den Hof, zu Hoftagen oder Heerzügen, der König und sein Gefolge hatten ein beschwerliches Itinerar zu bewältigen. Beide Gruppen bewirkten auf diese Weise die Integration riesiger Reiche, die sich über wochen- und monatelange Reisewege hinweg ausdehnten. Zeitweise während des früheren Mittelalters mochte es scheinen, daß dieser überregionale Zusammenhalt seine Dynamik verlieren würde, etwa im 7. und im 10. Jahrhundert. Doch jene Gebiete Europas, wo die Regionalisierung sich durchsetzte, waren daraufhin dem Zugriff von Mächten ausgesetzt, die von weither kamen, bis einer von ihnen eine neue Zentralisierung glückte. Süditalien im 10. Jahrhundert ist ein gutes Beispiel dafür. Man könnte diskutieren, ob manche Konstellationen des früheren Mittelalters als ,failed states' gelten können. Das betrifft aber kaum alle Staaten des Früh- und Hochmittelalters.

Die Interaktion der ebenso verstreuten wie vertrauten Führungsgruppen der Regna läßt sich in vieler Hinsicht als rituelle oder symbolische Kommunikation beschreiben. Ein Graf oder Bischof der Ottonenzeit konnte durchaus erwarten, auf einem Hoftag in voraussehbaren Abläufen seinen Rang in der symbolischen Hierarchie des Reiches bestätigt zu erhalten. Doch vielfach ging es zugleich um andere Interessen. Das Reich war für seine Führungsschichten nicht zuletzt ein Instrument zur Bereicherung und Besitzsicherung, es bot Chancen für Aufstieg und Karriere, Versorgung von Söhnen und Heiratsverbindungen für Töchter, zur Beeinflussung der lokalen Machtbalance und zum Erwerb neuer Positionen und Einflußgebiete, und möglicherweise lag ihnen sogar das Wohl des Reiches am Herzen. So sehr in der Forschung der siebziger Jahre materielle Interessen über Gebühr in den Vordergrund rückten, heute hat es zuweilen den Anschein, als müßte man solche Gemeinplätze in Erinnerung rufen.

Gerd Althoff hat in der Zusammenfassung seiner „Macht der Rituale“ diese Perspektive geöffnet, wenn er meint, es sei „bei allen Ritualen zu fragen, ob sie nicht Teil eines weitergehenden Geflechts von Absprachen und Entscheidungen waren" ".13 Daß Rituale verhandelbar waren, ist eine wesentliche Erweiterung seiner eigenen älteren Ansätze; der Begriff der ,negotiability` hat auch in der englischsprachigen Forschung derzeit Konjunktur. Was da verhandelt wurde, war nicht nur das richtige Ritual. Der reiche Bestand überlieferter Königsurkunden läßt eine Reihe weiterer Verhandlungsgegenstände erkennen. Was der Herrscher im Austausch für die von ihm ausgestellten Privilegien erhielt, ist oft weniger deutlich erkennbar. Zunächst ging es wohl um Konsens und Anerkennung, und damit erhöhte Durchsetzungsfähigkeit. Das konnte wiederum in rituellen Formen augenfällig gemacht werden. Spätestens seit Marcel Mauss ist die ethnologische Forschung davon ausgegangen, daß es beim Gabentausch nicht nur um den Gebrauchswert der Geschenke ging, und diese Erkenntnis hat auch die Mittelalterforschung weitergebracht. Daß es in Kriegergesellschaften mehr um Prestige als um Luxus gehen konnte, hat etwa Mario Erdheim am Beispiel der Azteken gezeigt. ${ }^{114}$ Doch sollte die materielle Dimension der ,Prestige-Ökonomie“ nicht vernachlässigt werden; gerade in den früh- und hochmittelalterlichen Reichen stellten königliche Landschenkungen, die Verleihung von Ämtern und anderes durchaus die Ressourcen für standesgemäßes Leben zur Verfügung.

113 Althoff, Macht der Rituale 202.

114 Mario Erdheim, Prestige und Kulturwandel. Eine Studie zum Verhältnis subjektiver und objektiver Faktoren des kulturellen Wandels zur Klassengesellschaft bei den Azteken (Wiesbaden 1973) 90. 
Hier könnten die Beobachtungen von Pierre Bourdieu bei den Kabylen weiterhelfen. Dort „reicht es für die Herrschenden nicht aus, das von ihnen beherrschte System laufen zu lassen, um ihre Herrschaft auf Dauer auszuüben; sie müssen täglich und persönlich daran arbeiten, die stets unsichere Herrschaftslage zu produzieren und zu reproduzieren"..115 Das setzt voraus, den Eigennutz zu verhüllen und in „ostentativer Rückverteilung“ das aus der Machtposition gewonnene ökonomische Kapital wieder zu verteilen, um andere persönlich an sich zu binden und damit „symbolisches Kapital“, also Prestige, Autorität und Handlungsspielraum zu gewinnen. Derjenige, der den höheren Rang beansprucht und daher das wertvollere Geschenk machen muß, ist dabei langfristig im Nachteil, da damit hohe Kosten verbunden sind und das progressive Schwinden der Herrschaftsmittel droht. Das gilt allerdings nur solange, als die Ressourcen der symbolischen Kommunikation nur aus dem engeren Verfügungsbereich der Partner kommen können, Werte darstellen, die durch die Gabe ,verloren' sind. Eine dauerhafte Institutionalisierung ist laut Bourdieu dann erreicht, wenn die ökonomischen Kosten der Gewinnung von symbolischem Kapital gesenkt werden können, weil abgesicherte Positionen innerhalb eines Systems anerkannter Ranghierarchien vergeben werden können. ${ }^{116}$

Der vormoderne Staat wäre in diesem Sinn als Rahmen zu beschreiben, der einen geordneten Erwerb von Rang und Würden, Rechten und Privilegien, also ,symbolischem Kapital' garantieren kann. Auch mittelalterliche Herrscher vergaben öfters ihre materiellen Ressourcen, um so ,symbolisches Kapital' zu erwerben. Doch zum Unterschied von archaischen Gesellschaften hatten sie auch umfassende Möglichkeiten, ,Ämter und Würden“ (im weiten Sinn von Thomas Zotz ${ }^{117}$ ), Rechte und Privilegien zu vergeben, ohne die Mittel des Reiches entscheidend zu schmälern. Königs- und Kaiserurkunden bieten dafür reiches Material. Neuere Studien zum Verhältnis von Königtum und kirchlichen Institutionen im Frühmittelalter zeigen etwa, daß der Zentralgewalt nicht unbedingt abgehen mußte, was Kirchen und Klöster erhalten hatten. ${ }^{118}$ Bourdieus Gedanke ist deswegen wertvoll, weil er eine Verknüpfung zwischen den ökonomischen Ressourcen der Herrschenden und dem Bereich der symbolischen Kommunikation anbietet. Dabei sieht er die Möglichkeit des Gelingens wie des Scheiterns vor, was nicht nur an falscher Politik, sondern auch an den jeweiligen institutionellen Möglichkeiten und Grenzen liegen kann.

Was bedeutet dieser Befund für die Frage nach den staatlichen Strukturen des Frühmittelalters? Für Althoff ähnelte die früh- und hochmittelalterliche Gesellschaft in vielem der „vorstaatlichen Stufe menschlichen Zusammenlebens" ${ }^{119}$ Die Rede von „Gesellschaften ohne Staat“, wenn auch zunächst bewußt plakativ gemeint, hat sich vor allem in der deutschen Hochmittelalter-Forschung verbreitet. ${ }^{120}$ In ähnlichem Sinn war schon zuvor von „une France sans état“ zwischen 1050-1200 die Rede. ${ }^{121} \mathrm{Al}-$ lerdings setzte diese Formulierung an der Idee einer „feudalen Anarchie“ im hochmittelalterlichen Frankreich an; Patrick Geary stellte demgegenüber den Nachweis von geregelter Konfliktaustragung, die vergleichbar mit den Befunden der Rechtsethnologie über außereuropäische Gesellschaften

115 Bourdieu, Sozialer Sinn 236. Vgl. Gerhard Göhler/Rudolf Speth, Symbolische Macht. Zur institutionentheoretischen Bedeutung von Pierre Bourdieu, in: Institutionen und Ereignis. Über historische Praktiken und Vorstellungen gesellschaftlichen Ordnens, ed. Reinhard Blänkner/Bernhard Jussen (Göttingen 1998) 17-48.

116 Dieses Modell ist insofern an die Mediävistik rückgekoppelt, als Bourdieu hier die Studien George Dubys zum Feudalismus als Beispiel dienten, was methodische Behutsamkeit nötig macht.

117 Thomas Zotz, In Amt und Würden. Zur Eigenart ,offizieller‘ Positionen im frühen Mittelalter, in: Tel Aviver Jahrbuch für deutsche Geschichte 22 (1993) 1-24.

118 Barbara Rosenwein, Negotiating Space. Power, Restraint, and Privileges of Immunity in Early Medieval Europe (Ithaca 1999); Matthew Innes, State and Society in the Early Middle Ages. The Middle Rhine Valley 400-1000 (Cambridge 2000) bes. $13-50$.

119 Althoff, Spielregeln 14; vorsichtiger ders., Macht der Rituale 13. Einen anderen, viel aktuelleren Vergleich zu Althoffs Bild vom Frühmittelalter stellt Len Scales, Rezension zu Althoff, Macht der Rituale, Early Medieval Europe 14, 3 (2005) 298-301 (hier 298) her: „The political landscape which Althoff conjures up, with its lobbyists, cronies, sofa government, high-level whitewash and face-saving, its rhetorical bluster, and its glossy, choreographical, dissent-free ,public sphere', certainly seems to a jaundiced reader to raise depressingly familiar echoes“.

120 Gert Althoff, Die Ottonen. Königsherrschaft ohne Staat (Stuttgart/Berlin/Köln 2000).

121 Geary, Vivre en conflit. 
ablief. ${ }^{122}$ Die Vorstellung von einer ottonischen Königsherrschaft ohne Staat wandte sich hingegen polemisch gegen überholte Auffassungen vom Hochmittelalter als Blütezeit des römisch-deutschen Kaiserstaates, auf die Jahrhunderte nationalen Niederganges folgten.

Die Abkehr von der triumphalistischen Kaisergeschichte ist nur zu berechtigt. Doch liegt eine ironische Pointe darin, daß die von der Ethnologie übernommene Formel ,Gesellschaften ohne Staat" jene Sozietäten bezeichnet, in denen tatsächlich keinerlei Zentralmacht bestand. ${ }^{123}$ Pierre Clastres sah in der Feststellung, eine Gesellschaft sei vorstaatlich, ein implizites Werturteil: „Ce qui en fait est enoncé, c'est que les sociétés primitives sont privées de quelque chose - l'état - qui leur est, comme à toute autre société - la notre par example - necessaire."124 Clastres bemühte sich an Hand indigener Gesellschaften Amerikas nachzuweisen, daß diese mit allerlei Mechanismen die Herausbildung von Herrschaft aktiv zu verhindern versuchten, nicht Gesellschaften ohne Staat, sondern gegen den Staat seien. Es gibt demnach durchaus differenziert organisierte Gemeinschaften, die herrschaftliches Handeln und überregionale Zusammenschlüsse zu straff organisierten politischen Einheiten in ihrer ,Verfassung ' gerade zu verhindern versuchen; ein Befund, der auch für manche Gesellschaften des Frühmittelalters von Bedeutung sein könnte, etwa bei den frühen Slawen. ${ }^{125}$

Eigentlich liegt ein deutsches Paradoxon darin: Die Ethnologie vorstaatlicher Organisation dient zur Analyse imperialer Herrschaftsentfaltung als Selbst-Inszenierung in einer archaischen Gemeinschaft und wird so zum Instrumentarium einer Reichsgeschichtsschreibung, die sich an den traditionellen Fragen - 918, 962, 1002 etc. - abarbeitet. ${ }^{126}$ Eine solche historische Anthropologie der Staatlichkeit bietet zweifellos einen reizvollen Kontrast zur älteren institutionengeschichtlichen Sicht des mittelalterlichen Staates. Sie hat geholfen, viel Wesentliches über das Funktionieren der symbolischen Kommunikation innerhalb der Eliten des 10. Jahrhunderts zu entdecken. Doch sollte einzelnen anthropologischen Kategorien (etwa der des Rituals) kein zu hoher Erklärungswert aufgebürdet werden. Vor allem nicht-diskursive und nicht-reflexive Formen der Kommunikation und Interaktion können kaum aus sich heraus zur Erklärung des sozialen Gesamtzusammenhangs dienen. Zudem ist Achtsamkeit geboten: Der Import ethnologischer Theorien in die Mediävistik kann Bilder von einem archaischen, schriftlosen und unbewußten Frühmittelalter verfestigen, ähnlich wie früher die Projektion moderner Staats- und Rechtsvorstellungen die Modernität des Mittelalters überzeichnete.

\section{GENS UND REGNUM}

Die Möglichkeiten eines früh- und hochmittelalterlichen Reiches können nicht an den Machtmitteln des modernen Staates gemessen werden. Aber sie liegen ebensoweit von denen archaischer, segmentärer Gesellschaften ,ohne Staat' entfernt. Es erscheint nicht abwegig, bei aller Vorsicht vor modernen Projektionen und Obertönen des Begriffes das politische System der Regna als ,Staat' zu bezeichnen. Die „Nützlichkeit einer Diskussion über Bezeichnungen und Etiketten“ hat schon František Graus bezweifelt. ${ }^{127}$ Will man jedoch den Staatsbegriff auf den modernen Staat beschränken, so müßte man einen anderen Begriff für das politische System frühmittelalterlicher Reiche finden. Die deutsche Forschung behilft sich gerne mit dem dem Begriff ,Reich', der allerdings kaum weniger Obertöne hat und zudem Übersetzern in andere Sprachen heikle Entscheidungen wie zwischen ,kingdom‘ und ,empire‘ abverlangt. Für die Reiche der Goten, Franken oder Langobarden hat sich, besonders in der englischsprachigen Forschung, der Quellenbegriff Regna eingebürgert. In Deutsch-

122 Geary, Vivre en conflit; Simon Roberts, Order and Dispute: An Introduction to Legal Anthropology (Harmondsworth 1979).

123 Gesellschaften ohne Staat, ed. Kramer/Sigrist.

124 Pierre Clastres, La société contre l'état (Paris 1974) 161; gegen Jean-William Lapierre, Essai sur le fondement du pouvoir politique (Aix-en-Provence 1968).

125 Vgl. Walter Pohl, Die Awaren. Ein Steppenvolk in Mitteleuropa, 567-822 n. Chr. (München 22002) $126 \mathrm{f}$.

126 Ähnlich schon Peter Johanek, Mittelalterforschung in Deutschland um 2000, in: Mediävistik im 21. Jahrhundert. Stand und Perspektiven der internationalen und interdisziplinären Mittelalterforschung, ed. Hans-Werner Goetz/Jörg Jarnut (Mittelalter-Studien 1, München 2003) 21-33.

127 Graus, Verfassungsgeschichte des Mittelalters 587. 
land wiederum hat sich um den Begriff regnum die bereits erwähnte Kontroverse zwischen HansWerner Goetz und Johannes Fried entsponnen, ob darin ein abstraktes Staatsverständnis enthalten ist. $^{128}$

Eine Untersuchung des Gebrauchs von regnum bei Paulus Diaconus, einem der angesehensten Intellektuellen im Umkreis Karls des Großen, zeigt die Vielfalt der Wortbedeutungen. ${ }^{129}$ Aufgabe des Königs war, laut Paulus, regnum regere utiliter. ${ }^{130}$ Seine Herrschaft ,war' also nicht nur das Regnum, dieses stand ihm auch gegenüber als dasjenige, worüber er herrschte. Ein solcher figurativer Gebrauch des Wortes ist häufig, auch in zahlreichen zusammengesetzten Formulierungen wie regni gubernacula. Oft kann das regnum auch territorial verstanden werden; Venantius Fortunatus etwa flieht ad Francorum regnum, oder die Usurpation des Alahis löst in regno Langobardorum großes Blutvergießen aus. ${ }^{131}$ Interessant ist, wie die Quellen den Übergang des langobardischen Königtums an die Franken beschreiben. ${ }^{132}$ Paulus als Zeitgenosse der fränkischen Eroberung des Langobardenreiches berichtet davon leider nicht direkt, sondern bloß im Gewand einer Prophezeiung: gens ipsa peribit. ${ }^{133}$ Darin kommt die Vorstellung zum Ausdruck, daß die Gens die maßgebliche Trägerin der politischen Macht war. ${ }^{134}$ Der Prolog der Kapitularien des Adelchis von 866 formuliert retrospektiv präziser, daß das Volk der Franken (Gallorum gens) primatum et capud (sic!) regni illius (sc. gentis Langobardorum) invasit, also dessen Vormachtstellung und Spitze an sich riß. ${ }^{135}$ Daß hinter solchen Formulierungen keinerlei transpersonale Vorstellungen steckten, ist schwer vorstellbar. Die Gens und nicht nur ein König/tum ergreift die Herrschaft.

Ambivalenz und ideologische Last der Begriffe Gens/Volk haben es der jüngeren Forschung leicht gemacht, sich seiner in der Diskussion politischer Ordnungsprinzipien zu entledigen. ${ }^{136}$ Die ältere Forschung wollte politische Institutionen prinzipiell vom Volk ableiten und hat sich damit in Irrwege und Mystifikationen verstrickt. ${ }^{137}$ Gerade die „Konzentration des Blicks auf Volk und Stamm, ihre Stilisierung zu überzeitlichen Handlungsträgern und die anhaltende, gleichsam mythisch begründete Axiomatik von deutscher Wesensart in der europäischen Geschichte" hat ja, wie Bernd Schneidmüller dargelegt hat, zur „intellektuellen Krise“ der deutschen Verfassungsgeschichte um 1970 geführt. ${ }^{138}$ Es ist nur zu verständlich, daß in Reaktion darauf die politische Rolle der Gens gerne vernachlässigt wird. Doch hat die neuere Forschung viel dazu beigetragen, Volk und Nation zu historisieren, als kom-

128 Siehe auch den Beitrag von Hans-Werner Goetz in diesem Band.

${ }^{129}$ Die Vielfalt der Konzepte von Regnum im exegetischen Schrifttum des 7.-13. Jahrhunderts zeigt Renate Pletl, Irdisches Regnum in der mittelalterlichen Exegese. Ein Beitrag zur exegetischen Lexikographie und ihren Herrschaftsvorstellungen (7.-13. Jahrhundert) (Frankfurt 2000), bes. 208-13.

130 Paulus Diaconus, Historia Langobardorum III, 34 (ed. Ludwig Bethmann/Georg Waitz, MGH SS rer. Langob. et Ital., saec. VI-IX, Hannover 1878) $112 \mathrm{f}$.

131 Paulus Diaconus, Historia Langobardorum I, 24; II, 4; III, 6; IV, 46; V, 34; V, 36, ed. Bethmann/Waitz 61 f.; 74; $95 ; 135 ; 156$. Ähnliche territoriale Formulierungen finden sich auch in den Leges Langobardorum, z. B. Edictus Rothari 367 (ed. Friedrich Bluhme, MGH LL 4, Hannover 1868) 85: in regni nostri finibus; Aistulf, Prologus de anno quinto, ebd. $197 \mathrm{f}$.: convocatis ex diversis partibus regni nostri pertinentibus iudicibus.

132 Siehe künftig Walter Pohl, Vom langobardischen zum fränkischen Italien: Herrschaft, Text und Identität.

133 Paulus Diaconus, Historia Langobardorum V, 6, ed. Bethmann/Waitz 147.

${ }^{134}$ Herwig Wolfram, Intitulatio I. Lateinische Königs- und Fürstentitel bis zum Ende des 8. Jahrhunderts (MIÖG Erg.Bd. 21, Köln/Wien 1967) 95.

135 Capitula domni Adelchis (ed. Friedrich Bluhme, MGH LL IV, Hannover 1868) 210.

${ }^{136}$ Siehe u. a. Walter Pohl, Telling the difference: Signs of ethnic identity, in: Strategies of Distinction: the Construction of Ethnic Communities, 300-800, ed. Walter Pohl/Helmut Reimitz (The Transformation of the Roman World 2, Leiden/Boston/ Köln 1998) 17-69; Matthias Becher, Rex, Dux und Gens: Untersuchungen zur Entstehung des sächsischen Herzogtums im 9. und 10. Jahrhundert (Husum 1996); und die Beiträge in MIÖG 108 (2000) von Matthias Becher (Volksbildung und Herzogtum in Sachsen während des 9. und 10. Jahrhunderts, 67-84), Hans-Werner Goetz (GENTES. Zur zeitgenössischen Terminologie und Wahrnehmung ostfränkischer Ethnogenese im 9. Jahrhundert, 85-116), Thomas Zotz (Ethnogenese und Herzogtum in Alemannien [9.-11. Jahrhundert], 48-66) und Bernd Schneidmüller (Völker - Stämme - Herzogtümer. Von der Vielfalt der Ethnogenesen im ostfränkischen Reich, 31-47).

137 Schlesinger, Die Grundlegung der deutschen Einheit 284.

138 Schneidmüller, Von der deutschen Verfassungsgeschichte zur Geschichte politischer Ordnungen 493. 
plexe Konstruktionen zu erweisen und ihre bruchhafte Entwicklung zu erschließen. ${ }^{139}$ Auf dieser Grundlage sollte neu über die Rolle ethnischer Verbände und Kategorien für staatliche Gemeinschaften des Mittelalters nachgedacht werden.

Der Quellenbefund ist jedenfalls eindeutig. Politisches Handeln wird oft der Gens als Kollektiv zugeschrieben, wobei diese Rolle am markantesten hervortritt, wenn ein König erhoben werden soll: Langobardi regem sibi statuerunt, heißt es wiederholt bei Paulus Diaconus. ${ }^{140}$ Sonst ist in der Historiographie oft gleichbedeutend, ob der König oder die Gens als handelnd beschrieben wird. Man kann diese Äquivalenz kaum als Ausdruck einer Unfähigkeit zum Erfassen abstrakter Organisationsformen betrachten (der Befund müßte dann gleichermaßen für heutige Journalisten gelten, die etwa Bush gegen Saddam Krieg führen ließen). Sicherlich kann die implizierte Geschlossenheit der handelnden Gens als ideologisches Konstrukt betrachtet werden, doch das ist schon an sich ein interessanter Befund.

Gerade wo eine frühmittelalterliche Gens politisch handelt, ist sie nicht, wie früher selbstverständlich angenommen, eine konkrete, abgrenzbare Gemeinschaft, sondern eine abstrakte Einheit, die unterschiedlich gefaßt werden kann. ${ }^{141}$ Die innere Gegliedertheit frühmittelalterlicher Gentes und Regna erlaubt keine eindeutige Abgrenzung. Die gens Francorum oder Langobardorum des 8. Jahrhunderts war im engsten Sinn eine Gruppe von einigen hundert oder höchstens tausend Menschen: Pippinus ... omnes Francos, sicut mos Francorum est, ... ad se venire praecepit. ${ }^{142}$ Das entspricht ungefähr den 150 bis 200 Mitgliedern der „politischen Gemeinschaft“, die Timothy Reuter als „Überbau“ des Ottonenreiches angenommen hat, die allerdings ethnisch wesentlich schwieriger zu umschreiben waren. ${ }^{143}$ Auf der anderen Seite kann die gens auch einen wesentlich weiteren, jeweils unterschiedlich abgegrenzten Verband beschreiben, bis hin zu sämtlichen Einwohnern der Francia oder des Langobardenreiches. ${ }^{144}$ Das war für gebildete Zeitgenossen umso schwieriger, als innerhalb des lateinischen politischen Diskurses die Rolle der Gens bei der Fundierung von Herrschaft im Frühmittelalter neue Begriffsdeutungen und rhetorische Strategien erforderte. ${ }^{145}$ Die Folge war im 5.-8. Jahrhundert eine flexible und oft geradezu experimentelle Staatssprache. Das läßt sich etwa an der Herrscher-Titulatur ablesen, die zunächst zwischen dem absoluten und dem gentilen Königstitel (rex oder rex Francorum) schwankt und ihn verschiedentlich durch römische Elemente wie patricius, flavius, vir inluster ergänzt, in denen die Legitimation gegenüber der romanischen Bevölkerungsmehrheit zum Ausdruck kommen soll. ${ }^{146}$ Der Kaisertitel Karls des Großen ist in gewisser Weise Höhepunkt und Abschluß dieser staatsrechtlichen Versuchsreihe. Das Ringen um eine abgestufte Definition von Herrschaftsansprüchen, das in der Intitulatio zum Ausdruck kommt, geht über ein rein personales Herrschaftsver-

139 Für die hochmittelalterliche Geschichte Deutschlands im Vergleich zu seinen Nachbarländern waren die Arbeiten des Nationes-Kreises mit insgesamt neun Bänden bahnbrechend: Nationes 1-9, ed. Helmut Beumann/ Werner Schröder (Sigmaringen 1975-91); siehe den Rückblick bei Schneidmüller, Von der deutschen Verfassungsgeschichte zur Geschichte politischer Ordnungen 493-496. Die ethnischen Prozesse des Frühmittelalters untersuchte die ,Wiener Schule um Herwig Wolfram; siehe u. a. ders., Die Goten. Von den Anfängen bis zur Mitte des 6. Jahrhunderts (Wien/München ${ }^{4} 2001$ ); ders., Typen der Ethnogenese. Ein Versuch, in: Die Franken und die Alemannen bis zur „Schlacht bei Zülpich“ (496/97), ed. Dieter Geuenich (RGA Erg.Bd. 19, Berlin/New York 1998) 608-627; Pohl, Tradition, Ethnogenese und literarische Gestaltung. Siehe auch Otfrid Ehrismann, Volk. Mediävistische Studien zur Semantik und Pragmatik von Kollektiven (Göppingen 1993).

140 Paulus Diaconus, Historia Langobardorum I, 14; III, 16 ed. Bethmann/Waitz 54; $100 \mathrm{f}$.

141 Walter Pohl, Ethnicity, theory and tradition: a response, in: On Barbarian Identity - Critical Approaches to Ethnogenesis Theory, ed. Andrew Gillett (Turnhout 2002) 221-240.

142 Continuationes Fredegarii 37 (ed. Bruno Krusch, MGH SS rerum Merovingicarum 2, Hannover 1888) 183.

143 Reuter, König, Adelige, Andere 137.

144 Walter Pohl, Zur Bedeutung ethnischer Unterscheidungen in der frühen Karolingerzeit, in: Studien zur Sachsenforschung 12 , ed. Hans-Jürgen Hässler (Oldenbourg 1999) 193-208.

145 Nikolaus Staubach, Germanisches Königtum und lateinische Literatur vom fünften bis zum siebenten Jahrhundert, in: Frühmittelalterliche Studien 17 (1983) 1-54; Walter Pohl, Die Völkerwanderung. Eroberung und Integration (Stuttgart/Berlin/ Köln 2002).

${ }^{146}$ Wolfram, Intitulatio I. Zum Problem des ,gentilen` Königstitels: Andrew Gillett, Was ethnicity politicized in the earliest medieval kingdoms, in: On Barbarian Identity. Critical Approaches to Ethnicity in the Early Middle Ages, ed. ders. (Turnhout 2002) 85-122. 
ständnis weit hinaus. Abgestuft war, wie erwähnt, auch die Bevölkerung eines Reiches, von den Franken oder Langobarden im engeren und weiteren Sinn über die anderen Untertanen barbarischer Herkunft, die in vereinzelten Dörfern oder in einigermaßen geschlossenen größeren Verbänden lebten, bis zu den ehemaligen Provinzialen, die wir heute, eigentlich zu pauschal, Romanen nennen. ${ }^{147}$ Das Regnum umfaßte sie alle, nicht unterschiedslos im Sinn einer modernen Staatsbürgerschaft, aber dennoch deutlich unterschieden von denen, die nicht dem Regnum angehörten.

Man könnte diese ethnische Komplexität als Zeichen eingeschränkter oder fehlender Staatlichkeit interpretieren. Doch zwang sie zu einer gewissen Abstraktionsleistung, denn das Regnum, in gewissem Maß auch die Gens mußten alle diese unterschiedlichen Gruppen und Verbände umgreifen und integrieren. Das war nicht bloß ein simpler Personenverband. Gerade in politischen Konflikten und Umbrüchen wurde sichtbar, wie prekär die Übereinstimmung von rex, regnum und gens war. Am Schnittpunkt dieser drei Begriffe läßt sich die Vorstellung von einem handelnden Kollektiv erkennen, das zugleich den politischen Raum für die Ambitionen seiner Angehörigen bildet. ${ }^{148}$ Von Anfang an trug die Ecclesia zur Integration der Regna auf römischem Boden bei und entfaltete ihr Identitätspotential im karolingischen Reich (siehe den Beitrag von Mayke de Jong in diesem Band). ${ }^{149}$ Bis heute geht die Forschung von einem Gegensatz zwischen ,gentilen' und universalen Tendenzen, zwischen Gens und Populus, zwischen Regnum und Imperium, aber auch zwischen Kircheneinheit und landeskirchlichen Bestrebungen aus. Dieses Modell mag manches erklären, verstellt aber zugleich den Blick dafür, daß alle diese übergreifenden Identitäten nur ausnahmsweise in Widerspruch zueinander gerieten. In der Karolingerzeit umschrieben gens Francorum, Imperium Romanum und populus Christianus überlappende Identitätsentwürfe, die zumindest vom Anspruch her zur Deckung kommen sollten.

Regnum und Gens waren also vielfach aufeinander bezogen, aber nicht deckungsgleich. ${ }^{150}$ Es mag schon stimmen, daß bei den Normannen die fränkische Erwartung, mit einem König und seiner Gens zu tun zu haben, zu schweren Fehleinschätzungen führte. ${ }^{151}$ Doch war das deshalb möglich, weil diese Vorstellung sich anderswo bewährt hatte. Karl der Große mußte rex Langobardorum werden, um Gens und Regnum der Langobarden unter Kontrolle zu bekommen. Der gotische, später langobardische und dann fränkische dominus, dann rex Italiae zeigen besonders deutlich, daß der ethnische, der personale und der institutionell-territoriale Aspekt dieses Königtums in einem Spannungsverhältnis zueinander blieben. Als lineare Entwicklung von personaler zu transpersonaler Herrschaft ist dieser komplexe Prozeß nicht zu beschreiben. ${ }^{152}$ Erfolgreich verlief hingegen die ethnische Integration der Bevölkerungsmehrheit. In Norditalien, in der Lombardei, kam diese Entwicklung zu einer territorialen langobardischen Identität paradoxerweise unter fränkischer Herrschaft zu einem Abschluß, ähnlich wie ein Jahrhundert später in Sachsen. ${ }^{153}$ Ebenso widersprüchlich verliefen die Entwicklung zu einer ,romanischen“ fränkisch-französischen Identität in Gallien und die Ent-Frankisierung des Ostfrankenreiches, wo ein lange Zeit identitätsschwacher Theotisci/Teutonici-Begriff nur allmählich den politischen Raum füllte - gerade dann, als dieser eigentlich schon weitgehend zerfallen war.

147 Siehe zuletzt, aus archäologischer Sicht, Volker Bierbrauer, Romanen, in: RGA 2. Aufl. 25 (2003) 210-242. In zeitgenössischen Quellen sind Romani meist die Bewohner der Stadt Rom oder des byzantinischen Italien, während die anderen oft nach der civitas definiert oder nach Regionalbezeichnungen ethnisiert werden: Galli, Averni, Tusci, Marsi, Norici etc., vgl. Walter Pohl, Le identità etniche nei ducati di Spoleto e Benevento, in: I Longobardi dei ducati di Spoleto e Benevento, Atti del XVI congresso internazionale di studi sull'alto medioevo (Spoleto 2003) 79-103. Die deutsche Wissenschaftssprache hat nicht zufällig für den Begriff Romani mehrere Übersetzungen: Römer, Romanen und Rhomäer.

148 Regna et Gentes. The Relationship between Late Antique and Early Medieval Peoples and Kingdoms in the Transformation of the Roman World, ed. Hans-Werner Goetz/Jörg Jarnut/Walter Pohl (The Transformation of the Roman World 13, Leiden/Boston/Köln 2003). Siehe dazu auch Karl Ferdinand Werner, Die ,Franken‘. Staat oder Volk?, in: Die Franken und die Alemannen bis zur „Schlacht bei Zülpich“ (496/97), ed. Dieter Geuenich (RGA Erg.Bd. 19, Berlin/New York 1998) 95-101.

149 Siehe auch Mayke de Jong, Charlemagne's Church, in: Charlemagne - Empire and Society, ed. Joanna Story (Manchester/ New York 2005) 103-35.

150 Early Medieval Kingship, ed. Peter H. Sawyer/Ian N. Wood (Leeds 1977).

151 Fried, Gens und Regnum 78-90.

152 So im klassischen Aufsatz von Helmut Beumann, Zur Entwicklung transpersonaler Staatsvorstellungen, in: Das Königtum. Seine geistigen und rechtlichen Grundlagen (Vorträge und Forschungen 3, 1956) 185-224.

153 Becher, Rex, Dux und Gens. 
Eine ,nationale‘ Grundlage der mittelalterlichen Staatsentwicklung läßt sich mit solchen Beobachtungen leicht widerlegen, und es verwundert, wie lange eine völkische Geschichtsdeutung daran festhielt. Eine kontroversielle Kontinuitätsdebatte verleitete dazu, die Regna entweder aus den Wäldern Germaniens herzuleiten oder als Fortsetzung römischer Herrschaft mit anderen Mitteln zu betrachten. Aus dem Blick geriet dabei, daß im 5. und 6. Jahrhundert eine ganz neue politische Konstellation entstanden war, bei der die politische Macht den Namen eines Volkes erhielt. In der klassischen Antike war das (sieht man von literarischen Stilisierungen einer römischen Gens ab) ebensowenig der Fall wie später in Byzanz oder den islamischen Reichen. ${ }^{154}$ Als Kollektivsubjekt erscheinen, quer durch alle Quellengattungen, Goten, Franken, Langobarden. Das Modell wurde im Lauf des Frühmittelalters mit biblischer Historia, klassischer Ethnographie und Fragmenten vorethnographischer Überlieferungen legitimiert und grundlegend für die Art und Weise, wie das Abendland mit ethnischen Identitäten und ihrer politischen Bedeutung umging. ${ }^{155}$ Letztlich wurden damit begriffliche Voraussetzungen des europäischen Nationalstaates geschaffen. Johannes Fried hat dargestellt, wie sich im frühmittelalterlichen Volksbegriff „eine ganze Sozialtheorie“ niederschlägt. ${ }^{156}$ Auch wenn die Gens zeitgenössisch als konkrete Abstammungsgemeinschaft verstanden wurde und keineswegs beliebig manipuliert werden konnte, war sie abstrakt und flexibel genug, um im Wandel politischer Ordnungen als Kommunikations- und Interaktionsrahmen verfügbar zu bleiben; nicht zuletzt, weil sie im Regnum ihren politischen Ausdruck und Gestaltungsraum fand.

Mit der Dualität von Regnum und Gens war immerhin ein Kriterium des modernen Staatsbegriffes erfüllt, nämlich „both the ordered community ... and the regime which does the ordering“ zu umfassen. ${ }^{157}$ Bei der Diskussion um den ottonischen ,Nicht-Staat' ist dieses Element deswegen in den Hintergrund getreten, weil hier der ethnische Bezug auf Franken/Sachsen, Bayern etc. besonders prekär ist: Die „Vielfalt der Ethnogenesen im ostfränkischen Reich“158 schuf mehrere politisch wirksame Identitätsebenen, was in Machtkämpfen mehrere Loyalitätsoptionen bedeuten konnte. Gerade der Erfolg der Franken, die Integration der rechtsrheinischen Völker und die Errichtung des Kaisertums, schuf Integrationsprobleme. Das Imperium umfaßte, wie schon zuvor das regnum Francorum, mehrere Regna. Die ethnische Frage im Reich des 10. und 11. Jahrhunderts ist zudem durch die alte Debatte um die Entstehung des deutschen Volkes belastet. ${ }^{159}$

Die Zeitgenossen waren sich des Problems durchaus bewußt. Der Continuator Reginonis versuchte als Grundlage ottonischer Herrschaft eine fränkisch-sächsische politische Identität zu entwerfen. Liutprand von Cremona rühmte sich, als Gesandter Ottos vor dem Kaiser im Konstantinopel die Roma$n i$ lächerlich gemacht und ihnen ein emphatisches, wir' gegenübergestellt zu haben - nos, Langobardi scilicet, Franci, Lotharingi, Bagoarii, Suevi, Burgundiones ${ }^{160}$ Doch sollte der ambivalente mehrstufige Gemeinschaftsbezug politischer Herrschaft nicht dazu führen, daß man ihn überhaupt außer Acht läßt und sich auf die rituelle Handhabung aristokratischer Netzwerke beschränkt. Aktionsrahmen und Motivationshorizont der politischen Akteure des Früh- und Hochmittelalters war in der Regel die Gens, aber nicht im Sinn eines überkommenen Stammesbewußtseins, sondern einer politischen Iden-

154 Vgl. Bernard Lewis, The Multiple Identities of the Middle East (New York 1998).

155 Arno Borst, Der Turmbau von Babel. Geschichte der Meinungen über Ursprung und Vielfalt der Sprachen und Völker, 4 Bde. (Stuttgart 1957-63); Pohl, Telling the difference; vorethnographische Überlieferungen: Herwig Wolfram, Auf der Suche nach den Ursprüngen, in: Die Suche nach den Ursprüngen. Von der Bedeutung des frühen Mittelalters, ed. Walter Pohl (Forschungen zur Geschichte des Mittelalters 9, Wien 2004) 11-22.

156 Fried, Gens und regnum $77 \mathrm{f}$.

157 Harding, Medieval Law 2.

158 Schneidmüller, Völker - Stämme - Herzogtümer.

159 Joachim Ehlers, Schriftkultur, Ethnogenese und Nationsbildung in ottonischer Zeit, in: Frühmittelalterliche Studien 23 (1989) 307-317; ders., Die Entstehung des deutschen Reiches (München 1994); ders., Methodische Überlegungen zur Entstehung des deutschen Reiches im Mittelalter und zur nachwanderzeitlichen Nationenbildung, in: Beiträge zur mittelalterlichen Reichs- und Nationsbildung in Deutschland und Frankreich, ed. Carlrichard Brühl/Bernd Schneidmüller (Historische Zeitschrift, Beihefte 24, München 1997) 1-14.

160 Continuatio Reginonis (ed. Friedrich Kurze, MGH SS rer. German. in us. schol. [50] Hannover 1890) 154-179; Liudprand of Cremona, Relatio de legatione Constantinopolitana 12 (ed. Paolo Chiesa, CCCM 156, Turnhout 1998 ) 193. 
tität, die von jeder Generation neu errungen und gedeutet werden mußte. ${ }^{161}$ Das Imperium schuf ab 800 einen konkurrierenden Bezugsrahmen, der in unterschiedlicher, meist aber eingeschränkter Weise angenommen wurde. Daß Widukind seine Sachsengeschichte gerade schrieb, als Otto I. am Höhepunkt seiner Kaisermacht lange Jahre in Italien verbrachte, ist nicht zufällig als Beharren auf den Aufgaben des Kaisers in der Heimat gelesen worden. ${ }^{162}$

Die Gens war nicht der, aber ein Angelpunkt frühmittelalterlicher Staatlichkeit. Sie stellt nur ein in der jüngeren Diskussion vernachlässigtes Element dar, da politische Organisation zu stark von der Herrschaft her gedacht wurde - selbst dort, wo anthropologische Terminologie gebraucht wurde. Im 4.-6. Jahrhundert hatten sich die Gentes und ihre Könige gegen ihre Konkurrenten im Westen des Imperiums durchgesetzt, da die ethnische Identität offenbar den Zusammenhalt auch in schwierigen Lagen verstärkte. ${ }^{163}$ Solche Ressourcen des inneren Zusammenhalts versuchten auch spätere Regna zu nützen. Doch das beruhte nicht auf der natürlichen Solidarität einer Volksgemeinschaft, wie man das früher glaubte, sondern auf einer Identitätspolitik, die gerade die Franken mit einigem Aufwand betrieben. ${ }^{164}$ Das Volk ist daher gerade nicht das Konkrete, wie es die deutsche Herrschaftslehre an die Stelle des abstrakten Staates setzen wollte. Es ist ein Konzept, mit dem den relativ flexiblen Gemeinschaftserfahrungen des frühen Mittelalters politische Gestalt gegeben, ein mitwirkungsberechtigter populus aus der Masse der Bevölkerung herausgehoben und zugleich die Gesamtbevölkerung des Reiches pauschal umschrieben werden sollte. Daß all diese Bestimmungen widersprüchlich blieben, braucht nicht zu überraschen, denn das kommt selbst nach jahrhundertelanger Entwicklung der modernen Nationalstaaten bis heute vor.

\section{HERRSCHAFTSDURCHSETZUNG UND ANDERE KRITERIEN FRÜHMITTELALTERLICHER STAATLICHKEIT}

Die Beiträge dieses Bandes versuchen unter anderem exemplarisch zu zeigen, daß das (wenn auch keineswegs spannungslose) Ineinandergreifen von Regnum, Gens und Ecclesia im Frankenreich und anderswo ein politisches System bildete, das einen durchaus stabilen, verbindlichen und überpersönlichen Rahmen für die Ausübung von Herrschaft darstellte. Aus verschiedenen Blickwinkeln entwerfen die Autoren Perspektiven einer komplexen politischen Ordnung vor allem im Karolingerreich. Was auf dessen Zerfall folgte, wird hier nicht genauer erörtert; man könnte deshalb einwenden, daß sich im 10. Jahrhundert die Probleme einer ,Herrschaft ohne Staat' anders und schärfer stellen. Doch das Problem der Konzepte von ,Staatlichkeit', um die es in diesem Beitrag geht, bleibt ähnlich.

In den meisten jüngeren Beiträgen zur Diskussion des früh- und hochmittelalterlichen Staates bleiben die angewandten Kriterien für mittelalterliche ,Staatlichkeit' mehr oder weniger implizit, gerade dort, wo die Bedeutung staatlicher Strukturen eher gering eingeschätzt wird. Versucht man die unausgesprochenen Voraussetzungen solcher Urteile explizit zu formulieren, kommt man zu einer Eingrenzung des Staatsbegriffes, die selbst über die meisten gängigen Definitionen des modernen Staates hinausgeht. Ein Staat setzt, nach diesem Modell, das abstrakte Bewußtsein zumindest seiner Gelehrten und Herrschenden von seiner ,transpersonalen“ Existenz voraus. Regionale Machtpositionen müssen grundsätzlich von der Staatsmacht abgeleitet sein, Amtsträger daher jederzeit absetzbar. Staatlichkeit erfordert die weitgehende Durchsetzung des Willens der Zentralgewalt und ihre institu-

161 Becher, Rex, Dux und Gens.

162 Bernd Schneidmüller, Widukind von Corvey, Richer von Reims und der Wandel politischen Bewußtseins im 10. Jahrhundert, in: Beiträge zur mittelalterlichen Reichs- und Nationsbildung in Deutschland und Frankreich, ed. Carlrichard Brühl/Bernd Schneidmüller (Historische Zeitschrift, Beihefte 24, München 1997) 83-102, bes. 91; ders., Völker - Stämme - Herzogtümer, bes. 44 f; Bernhard Zeller, Identitäten, Differenzen und Grenzen als Herausforderungen der ottonischen Historiographie. Studien zur Continuatio Reginonis und zu den Res Gestae Saxonicae (unveröff. Diss. phil., Wien 2003) 81-139.

163 Pohl, Völkerwanderung.

164 Helmut Reimitz, Die Konkurrenz der Ursprünge in der fränkischen Historiographie, in: Die Suche nach den Ursprüngen. Von der Bedeutung des frühen Mittelalters, ed. Walter Pohl (Forschungen zur Geschichte des Mittelalters 9, Wien 2004) 191-209; ders., Der Weg zum Königtum in den historiographischen Kompendien der Karolingerzeit, in: Der Dynastiewechsel von 751. Vorgeschichte, Legitimationsstrategien und Erinnerung, ed. Matthias Becher/Jörg Jarnut (Münster 2004) 277-320. 
tionell abgesicherte überlegene Macht, wenn der Staat schon kein Gewaltmonopol besitzt. Auflehnung gegen den König muß in jedem Fall illegitim sein. Konflikte um die Macht zeigen, zumindest wenn sie eine gewisse Intensität oder Häufigkeit annehmen, das Scheitern des Staates an, am schlimmsten dann, wenn sie innerhalb der kleinen Gruppe der Mächtigsten stattfinden. Der Staat ist begrifflich und institutionell von der Kirche und ihrer religiösen Autorität und Hierarchie geschieden - was meist als Leistung des Investiturstreits verbucht wird.

Als theoretischer Entwurf für die Kriterien des mittelalterlichen Staates würde sich dieses anspruchsvolle Modell wohl nicht so leicht durchsetzen lassen. Dennoch werden die Leistungen frühmittelalterlicher Staaten mehr oder weniger daran gemessen. ${ }^{165}$ Die überwältigende Realität des merowingischen oder ottonischen Reiches wird zumeist in der unkontrollierbaren Machtposition seiner Großen gesehen, gegen deren Herrschaft auch der König nur vergleichbare Ressourcen und Strategien, aber keine souveräne Autorität setzen konnte: Es gab kaum etwas, das seine Macht qualitativ von der ihren abhob. In dieser Hinsicht hat sich der Ansatz Dannenbauers weitgehend durchgesetzt. ${ }^{166}$ Zweifellos lassen sich die Schwierigkeiten der Könige mit der Adelsmacht im Früh- und Hochmittelalter vielfach belegen. ${ }^{167}$ Ein grundlegendes Problem des Mittelalters war die gesellschaftliche Kontrolle von „warlords“ mit bewaffnetem Gefolge und teils beträchtlichen Machtressourcen. Das hat Generationen von Historikern ermutigt, wie Matthew Innes es polemisch auf den Punkt bringt, „to view early medieval history in terms of the opposition between ,public' and ,private " power - the former a Good Thing identified with kings, the latter a Bad Thing exemplified by the aristocracy. Privileging public vs. private as an interpretative modality creates an ahistorical contrast between order and disorder, harmony and conflict, as the self-image of the modern state as the only guarantor of social peace is read back into the middle ages. " 168 Wenn die Aristokratie vor allem an der Stärkung der eigenen Macht auf Kosten der staatlichen Gemeinschaft interessiert war, fragt man sich, warum das Reich nicht in autonome Einzelherrschaften zerfiel, ähnlich wie das langobardische Fürstentum von Benevent, aus dem binnen weniger Jahrzehnte nach 840 eine verwirrende Vielfalt regionaler und lokaler Machthaber entstand, die auch an integrativen Ritualen kein Interesse mehr hatten. ${ }^{169}$ Der groBe Raum des Reiches blieb jedoch bestehen.

Die Konflikte der Mächtigen sind eine wichtige Herausforderung für jedes Staatskonzept. Zeigt ihr Überhandnehmen wirklich Schwäche, ja Nichtexistenz des Staates an? Immerhin hat gerade im ottonischen Imperium von den hochrangigen Teilnehmern der wiederholten Machtkämpfe kaum einer das Leben verloren, jedenfalls keiner der beteiligten Herrscher (dazu mußte man schon weit zu den Heiden reisen), die Sohneserbfolge blieb über vier aufeinanderfolgende Generationen gewahrt, und selbst langjährige Abwesenheit der Kaiser bewirkte zwar Proteste und Abnützungserscheinungen, nicht aber ihren Sturz oder gar einen Systembruch. Vielleicht hatten all die Machtkämpfe eine Funktion innerhalb des Systems? Das würde dem Modell Niklas Luhmanns entsprechen, der sozialen und politischen Konflikt als notwendige Triebkraft des Systemwandels beschrieben hat. Das System dient dabei als Orientierungsrahmen für Konflikte, die keineswegs das Versagen von Kommunikation anzeigen, sondern intensive Kommunikation von Widerspruch bedeuten. ${ }^{70}$ So werden Positionen verteilt und Rangordnungen sanktioniert, und Konflikte können zur Integration einer Gesellschaft dienen und müssen keineswegs die Schwäche ihres Zusammenhaltes anzeigen. Nicht bloß die rituellen Formen der Konfliktbewältigung, sondern die Konflikte selbst, die im Reich und um das Reich ausgetragen wurden, verstärkten bis zu einem gewissen Grad dessen Zusammenhang.

\footnotetext{
165 Vgl. Schneidmüller, Zwischen Gott und den Getreuen 223, der Klagen in der Forschung über die Schwächen mittelalterlicher Monarchien aus „den Prämissen einer neuzeitlichen Staatlichkeit jenseits der offenen Ordnungskonfigurationen des Mittelalters" herleitet.

166 Dannenbauer, Adel, Burg und Herrschaft.

167 Siehe etwa Reuter, König, Adelige, Andere.

168 Innes, State and Society $255 \mathrm{f}$.

169 Überblick: Kreutz, Before the Normans. Aus der Perspektive von Montecassino: Walter Pohl, Werkstätte der Erinnerung. Montecassino und die Gestaltung der langobardischen Vergangenheit (MIÖG Erg.Bd. 39, Wien/München 2001).

170 Luhmann, Soziale Systeme 529-550; Pohl, Konfliktverlauf und Konfliktbewältigung.
} 
Sowohl für das Reich der Merowinger als auch für das der frühen Karolinger ist gezeigt worden, daß Konflikte innerhalb der Dynastie dazu beitragen konnten, auch oppositionelle oder den Herrschaftszentren fernstehende Gruppen auf die Legitimität der Dynastie hin zu orientieren. ${ }^{171}$ Die teils blutigen Auseinandersetzungen der gallischen Bischofsdynastien, die Gregor von Tours beschreibt, fanden innerhalb des Frankenreiches statt, an dem sie sich orientierten, und das als Regulativ diente. ${ }^{172}$ Ähnliches dürfte auch auf viele Machtkämpfe der Ottonenzeit zutreffen. Die Konflikte zwischen Zentralgewalt und regionalen Gewalten im Langobardenreich waren nicht unbedingt Zeichen für die Schwäche der Königsherrschaft, sondern für das beträchtliche Potential sowohl des Königtums als auch konkurrierender Duces innerhalb einer Verdichtungszone langobardischer Herrschaft in der nördlichen Poebene. ${ }^{173}$ Solche Konflikte fanden innerhalb eines engen und selbst einigermaßen stabilen Rahmens politischer Kommunikation statt, den sie in der Regel nicht überschritten.

Frühmittelalterliche Staaten schufen solche Kommunikations- und Interaktionsräume, innerhalb derer einander Konflikte, Bündnisse, Verhandlungen, Versöhnung, Solidarisierung, gemeinsames Handeln und neue Zerwürfnisse abwechselten. Rituale und symbolische Kommunikation waren ein Aspekt dieser intensiven Auseinandersetzung innerhalb eines politischen Raumes. Umfassender ist die Interaktion innerhalb der Regna aber durchaus traditionell als ,Politik' zu beschreiben. Deren Instrumentarium ging über den rituellen und symbolischen Bereich weit hinaus. Die zeitgenössischen Quellen schildern die politische Kommunikation in ihrer ganzen Breite, von Gewalt (deren Rolle nicht vergessen werden sollte ${ }^{174}$ ), List und Hinterhalt bis zu Interessenausgleich, kontroversen Verhandlungen und sachlicher Auseinandersetzung.

Politischer Erfolg und Mißerfolg, Durchsetzung der Zentralgewalt oder Widerstand greifen als Kriterium für die Existenz einer staatlichen Ordnung zu kurz. Gerade Konflikte und Mißerfolge zeigen an, ob ein politisches System dauerhaft funktionsfähig ist. ,Staat‘ wäre dann das, was das Scheitern seiner Herrscher überdauert. Wipos Aussage zur Plünderung des Palastes in Pavia nach dem Tod Heinrichs II. wurde in diesem Sinn als Anbruch einer neuen Zeit transpersonalen Staatsverständnisses gedeutet; ${ }^{175}$ doch handelten die politischen Verantwortlichen frühmittelalterlicher Reiche immer schon dementsprechend. Selbst als 774 das Langobardenreich ,unterging', blieb die Kontinuität des Namens und aller wesentlichen Institutionen gewahrt. Sie wurden nur allmählich mit fränkischen Amtsträgern besetzt. Auch das Scheitern Ottos III. und die ,Wende'von 1002 hatten keinen Systembruch zur Folge. ${ }^{176}$ Machtkämpfe innerhalb der Regna, Auflehnung und Usurpation bedeuteten ja auch allenfalls, daß existierende Positionen und Ressourcen neu verteilt wurden. In der jüngeren Forschung ist es gelungen, sehr differenziert die jeweiligen Veränderungen in der Reichweite herrscherlichen Zugriffs nachzuzeichnen, etwa den „Kontrollverlust der Zentralgewalt“ am Beginn der Ottonenzeit ${ }^{177}$ oder die „Zentralisierung der Herrschergewalt“ unter Heinrich II. ${ }^{178}$ Eine stetige Entwicklung der Staatlichkeit läßt sich daraus kaum mehr ablesen.

${ }^{171}$ Innes, State and Society; Ian Wood, Deconstructing the Merovingian family, in: The Construction of Communities in the Early Middle Ages - Texts, Resources, Artifacts, ed. Richard Corradini/Max Diesenberger/Helmut Reimitz (The Transformation of the Roman World, Leiden/Boston 2003) 149-172; Stuart Airlie, Towards a Carolingian aristocracy, in: Der Dynastiewechsel von 751. Vorgeschichte, Legitimationsstrategien und Erinnerung, ed. Matthias Becher/Jörg Jarnut (Münster 2004) 109-127.

172 Helmut Reimitz, Social networks and identities in Frankish historiography. New aspects of the textual history of Gregory of Tours' Historiae, in: The Construction of Communities in the Early Middle Ages - Texts, Resources, Artefacts, ed. Richard Corradini/Max Diesenberger/Helmut Reimitz (The Transformation of the Roman World 12, Leiden/Boston 2002) $229-268$.

173 Chris Wickham, Land and Power. Studies in Italian and European Social History, 400-1200 (London 1994) bes. 99-118.

174 Halsall, Violence and Society.

175 Beumann, Zur Entwicklung.

176 Otto III. - Heinrich II. Eine Wende?, ed. Bernd Schneidmüller/Stefan Weinfurter (Sigmaringen ${ }^{2} 2000$ ). Siehe besonders Bernd Schneidmüller, Otto III. - Heinrich II. Wende der Königsherrschft oder Wende der Mediävistik?, ebd. 9-46.

177 Siehe die Beiträge des Bandes Ottonische Neuanfänge, ed. Schneidmüller/Weinfurter, besonders Reuter, König, Adelige, Andere $128 \mathrm{f}$.

178 Stefan Weinfurter, Die Zentralisierung der Herrschaftsgewalt im Reich durch Kaiser Heinrich II., in: ders., Gelebte Ordnung - gedachte Ordnung. Ausgewählte Beiträge zu König, Kirche und Reich (Sigmaringen 2005) 213-264 (Erstveröffentl.: in: Historisches Jahrbuch 106 [1986] 241-297); ders., Authority and legitimation of royal policy and action: the case of Henry II., 
Konflikte innerhalb der ,politischen Gemeinschaft' wurden bereits von den Zeitgenossen in der Regel als Kampf um die Macht innerhalb des Königreichs verstanden und von äußeren Auseinandersetzungen geschieden. Nach der Systemtheorie wären Regna dann selbstreferentielle Systeme (Systeme, die sich selbst als solche wahrnehmen), wenn sie „die Differenz von System und Umwelt systemintern als Orientierung und als Prinzip der Erzeugung von Informationen verwenden können“. ${ }^{179}$ Hier ist also nicht die Konzeption des Systems als abstrakte, überpersönliche Einheit gefordert, sondern bloß die Abgrenzung nach außen als Orientierungsgrundlage. „Identität und Differenz“, das belegen die zeitgenössischen Quellen vielfach, wurden in den Regna in ausreichendem Maß produziert, um ihre Selbstreferentialität zu begründen. ${ }^{180}$ Die Differenz gegenüber dem Anderen wird durch Sinngrenzen vermittelt, die kollektive Handlungsfähigkeit herstellen. An den Identitäten, die innerhalb dieser Sinngrenzen entstehen, werden gewisse Erwartungen festgemacht, was soziale Rollen prägt und bis zu einem gewissen Grad Erwartungssicherheit schafft. ${ }^{181}$

Vielleicht ist es mit Hilfe des Begriffes der ,sozialen Rollen“ möglich, eine Vermittlung zwischen den Denkmodellen zu finden, die den ,staatlichen' Zusammenhang des früheren Mittelalters entweder in der Regelhaftigkeit institutionellen Handelns oder aber in der rituellen Interaktion von Personen begründet sehen. Beide Gesichtspunkte erfassen durchaus wesentliche Aspekte mittelalterlicher Lebensordnungen, aber eben nicht deren Kern. W. G. Runciman definiert soziale Rollen als „positions embodying consistently recurring patterns of institutional behaviour". Das institutionelle Handeln beschreibt er als „Praktiken“ („functionally defined units of reciprocal action“), beide zusammen bilden die Grundkategorien der Macht. Historischer Wandel geschieht durch die „competitive selection of practices“, also die Bewährung bestimmter Aktionsmuster in der jeweiligen Situation und ihre Anpassung daran. ${ }^{182}$ Es sind diese wiederholten Grundmuster, die den sozialen Zusammenhang herstellen. Eine solche neutrale Definition von sozialen Rollen und Praktiken umfaßt Rechtsnormen ebenso wie Rituale, symbolische Kommunikation und Herrschaftsrepräsentation, doch beschränkt sie sich nicht auf symbolische, im wesentlichen nicht-diskursive Handlungen. Der rechtshistorische Ansatz, in der Formulierung von Reinhart Koselleck, sieht die „Wiederholbarkeit kraft Rechtsregeln“, die institutionelle Gebundenheit als entscheidendes Element jeder Verfassung. ${ }^{183}$ Die Ritual-Theorie sucht die Berechenbarkeit von politischem Handeln in den ,Spielregeln“ symbolischer und ritueller Kommunikation, was den Horizont wesentlich erweitert. Doch Erwartungssicherheit wurde nicht nur durch Rechtsregeln und durch Rituale hergestellt. Ein allgemeines Modell des ,staatlichen' Zusammenhanges im Mittelalter muß alle Handlungsmuster umfassen, die in berechenbarem wechselseitigem Handeln Identität nach innen und Differenz nach außen schaffen und verfestigen.

Methodisches Problem bei der Untersuchung sozialer Rollen ist es, daß Geschichtsschreiber gerade ,wiederholte Muster" meist voraussetzen und nicht extra berichtenswert finden. Auf der anderen Seite haben sie meist ein außerordentlich feines Sensorium dafür, in welchem Maß das Verhalten einer Person den Erwartungen an seine soziale Rolle entsprach. Dieses Spannungsverhältnis von Person und sozialer Rolle ist im Modell des ,Personenverbandsstaates“ unzulänglich erfaßt. Dieses legt zwar Ausgangspositionen der „Personen, die ausgestattet mit ursprünglichen, eigenen Rechten in den Staat eingegliedert werden“, fest; ${ }^{184}$ doch die Betonung der autogenen Adelsmacht verstellt ein Verständnis der ,reziproken Handlungsmuster zwischen König und Eliten. Ein traditionelles Verständnis von Rechtsnormen und Institutionen wiederum kann von der Vielfalt der "Praktiken' nur jene erfassen, die abstrakten Normen entsprachen und sozusagen, von Amts wegen` erfolgten. Der Überblick über die Viel-

in: Medieval Concepts of the Past. Ritual, Memory, Historiography, ed. Gerd Althoff/Johannes Fried/Patrick Geary (Cambridge 2002) 19-38.

179 Luhmann, Soziale Systeme 25.

180 Walter Pohl, Aux origines d'une Europe ethnique: Identités en transformation entre antiquité et moyen âge. Annales HSS (1/2005) 183-208.

181 Luhmann, Soziale Systeme 269-274; 426-436.

182 Runciman, A Treatise on Social Theory 3 ; 41; dazu Wickham, Systactic structures.

183 Reinhart Koselleck, Begriffsgeschichtliche Probleme der Verfassungsgeschichtsschreibung, in: Der Staat, Beiheft 6 (1983) 7-21, hier 11; vgl. Graus, Verfassungsgeschichte 545, Anm. 43.

184 Mayer, Ausbildung $289 \mathrm{f}$. 
falt der Bezeichnungen für das ,Amt` im früheren Mittelalter, den Thomas Zotz zusammengestellt hat, zeigt aber, daß die Aspekte von Dienst und Unterordnung (ministerium) dabei weniger verbreitet sind als die Einordnung in der Gesellschaft (ordo, dignitas), der persönliche Status (honor) und die Aufgaben und Wirkungen (officium, potestas). ${ }^{185}$ Neuere Ansätze der Erforschung mittelalterlicher Institutionen haben den Institutionenbegriff von einem modernen bürokratischen Verständnis abgelöst. ${ }^{186}$ Das geht bis hin zu praxeologischen Definitionen als „relativ auf Dauer gestellte, durch Internalisierung verfestigte Verhaltensmuster und Sinngebilde mit regulierender und orientierender Funktion “. ${ }^{87}$ Über das Modell der ,sozialen Rollen“ und ,Praktiken“ hinaus wird hier auch die Ebene der Sinngebung erschlossen. So verstanden, kann der Begriff ein weites Feld von ,institutioneller' Stabilität beschreiben.

Früh- und hochmittelalterliche Herrscher verfügten über einen durchaus beachtlichen Erfüllungsstab, wozu ein Netzwerk von Beauftragungen und Kooperationen mit Mitgliedern der Führungsschicht des Reiches kam, die ihre eigenen Interessen flexibel an diejenigen des Herrschers zu binden vermochten. ${ }^{188}$ Freilich erlaubte dieses System nur in beschränktem Maß die Durchsetzung der Königsherrschaft im ganzen Reich. Die Forschung hat meist in denjenigen Institutionen der mittelalterlichen Gesellschaft, die nicht direkt dem Zugriff des Königs ausgesetzt waren oder sich ihm allmählich entzogen, Beweise für die Schwäche der Zentralgewalt und damit des staatlichen Zusammenhanges gesehen. Die Erblichkeit von Ämtern und Lehen, Immunitäten von Klöstern und Kirchen, weltliche Aufgaben von Bischöfen, Zusammenschlüsse zu Einungen und Schwurgemeinschaften, der Aufstieg regionaler Adelsherrschaften, Mitwirkungsrechte der Fürsten bei der Reichsverwaltung, all das galt als Hemmschuh staatlicher Integration, die letztlich erst der moderne Absolutismus beseitigt habe.

Das ist freilich wieder stark von einer herrschaftlichen Auffassung des Staates her gedacht wie auch von einer entwicklungsgeschichtlichen Perspektive, die den (geraden) Weg vom mittelalterlichen zum modernen Staat sucht. Politische Integration wurde nicht nur autokratisch von oben durchgesetzt, sie stellte sich auch im Zusammenwirken verschiedener gesellschaftlicher Instanzen und Gruppen her. Die relative Stabilität von Rechten und Besitzverhältnissen, nicht zuletzt bei (mehr oder weniger) unbewaffneten kirchlichen und monastischen Institutitonen, verdankte sich einer Machtbalance, die einen ,staatlichen' Rahmen benötigte und dabei der Königsmacht Grenzen zog. In der deutschen Mediävistik wirkten lange die autoritären Wertungen nach, die darin das Scheitern des mittelalterlichen deutschen Staates begründet sehen. Die englische Mediävistik hat ähnliche Prozesse (z. B. den Weg zur Magna Charta) traditionell eher als Frühphase der Demokratieentwicklung gedeutet. Beide Urteile sind teleologisch, doch zumindest die herrschaftliche Definition des Staates sollte heute als überwunden gelten.

Als vorläufiges Ergebnis dieser Untersuchung können einige Gesichtspunkte und Kriterien frühmittelalterlicher Staatlichkeit festgehalten werden:

- Erstens die Dauerhaftigkeit: Bereits die frühesten Regna auf römischem Boden, etwa die der Vandalen, Burgunder oder Ostgoten, erreichten bei weitgehender Übernahme römischer Institutionen einige Stabilität; als ihre Könige militärischen Angriffen von außen unterlagen und die führende Gens ihre Stellung verlor, blieben viele Institutionen bestehen. ${ }^{189}$ Die nachfolgenden Reiche, vor al-

185 Zotz, In Amt und Würden. Vgl. auch Gideon Maier, Amtsträger und Herrscher in der Romania Gothica (Stuttgart 2005$)$, bes. $26-36$.

186 Reinhard Blänkner/Bernhard Jussen, Institutionen und Ereignis. Anfragen an zwei alt gewordene geschichtswissenschaftliche Kategorien, in: Institutionen und Ereignis. Über historische Praktiken und Vorstellungen gesellschaftlichen Ordnens, ed. dies. (Göttingen 1998) 9-16; Gerd Melville, Institutionen als geschichtswissenschaftliche Themen, in: Institutionen und Geschichte, theoretische Aspekte und mittelalterliche Befunde, ed. ders. (Köln 1992) 1-24.

187 Göhler/Speth, Symbolische Macht 18 (die Definition lag dem DFG-Schwerpunkt „Theorie politischer Institutionen“, 1989-95, zugrunde). Siehe auch Peter L. Berger/Thomas Luckmann, Die gesellschaftliche Konstruktion der Wirklichkeit (Frankfurt am Main 1980) 49-97.

188 Siehe den Beitrag von Stuart Airlie, in diesem Band, sowie Philippe Depreux, Prosopographie de l'entourage de Louis le Pieux, 781-840 (Sigmaringen 1997), bes. 27ff.; 41-64; Janet L. Nelson, Kingship and royal government, in: The New Cambridge Medieval History 2, c. 700-900, ed. Rosamond McKitterick (Cambridge 1995) 383-430.

189 Siehe den Beitrag von Ian Wood in diesem Band; vgl. auch Pohl, Völkerwanderung; Regna et Gentes, ed. Goetz/Jarnut/ Pohl. 
lem das der Franken, erreichten ein beträchtliches Maß an Kontinuität, auch über Herrschaftswechsel und Teilungen hinaus.

- Die Stabilität eines ,Staates“ sollte zweitens nicht nur an der Behauptungs- und Durchsetzungsfähigkeit der Herrschaft bemessen werden. Die Dauerhaftigkeit vieler nicht im engeren Sinn ,staatlicher' Institutionen - Bistümer, Klöster, Adels- und Grundherrschaften, Städte und Gemeinden beweist, daß ein früh- und hochmittelalterliches Regnum sehr wohl die Erwartungssicherheit in seiner Bevölkerung in beträchtlichem Ausmaß herstellen konnte. Das war nicht nur eine Leistung des Königtums, sondern im ,reziproken Handeln‘ aller Machtträger begründet.

- Drittens war das Regnum ein durchaus selbstreferentielles System, das selbstverständlich als handlungsfähige Einheit betrachtet wurde und an das sich Vorstellungen von Identität und Differenz knüpften, die es erlaubten, Innen- und Außenwahrnehmung zu unterscheiden. ${ }^{190}$ Wer zu einem Regnum dazugehörte, war weitgehend klar - oder, in Situationen politischer Instabilität, klärungsbedürftig. Der politische Raum eines Reiches war nicht überall eindeutig territorial fixiert und linear abgegrenzt (gerade in Expansionsgebieten wie dem slawischen Osten des 9. und 10. Jahrhunderts), aber in seiner Konfiguration weitgehend bekannt; dort, wo Zugehörigkeiten strittig waren, wie in den langobardischen Dukaten Spoleto und Benevent, im spätkarolingischfrühottonischen Lothringen oder im Böhmen des 10. Jahrhunderts, war auch das bewußt und Gegenstand politischen Handelns.

- Eine weitere Identitätsressource bildete viertens die Gens, auch wenn sie keineswegs deckungsgleich mit dem Regnum war (besonders bei den Franken, wo gerade der politische Erfolg der fränkischen Regna sie stärker von der gens Francorum abhob). Doch beruhte frühmittelalterliche Königsherrschaft in beträchtlichem Maß auf dem Wir-Gefühl, das sich an die Gens (oder die Gentes) knüpfte, und trug zugleich selbst wieder entscheidend dazu bei.

- Ähnliches gilt fünftens wohl auch für die Ecclesia, die als bewußt erlebte und vielfach stilisierte und diskutierte Gemeinschaft den umfassendsten Inbegriff aller Angehörigen eines Reiches darstellte, auch wenn sie zugleich darüber hinauswies auf den Horizont der gesamten Christenheit. ${ }^{191}$

- Die christliche ,Sprache der Gemeinschaft' erlaubte es sechstens ebenso wie die römische Staatssprache, Fragen der Macht und der richtigen Ordnung aufzuwerfen und teils kontrovers zu diskutieren. Dieser Diskurs der Macht verbirgt sich zum Teil in exegetischer Literatur, in Predigten, Synodalakten oder hagiographischen Handschriften oder ähnlichen Textsorten, was uns aber nicht dazu verleiten sollte, die Macht des Diskurses zu unterschätzen. ${ }^{192}$

- Siebtens bot das politische System der Regna einen Rahmen, in dem der relative Status (das, symbolische Kapital') der Mächtigen ausgehandelt werden konnte, ihre Ambitionen Platz fanden und ihre Konflikte begrenzt werden konnten. Dabei spielten Rituale, Gabentausch und symbolische Kommunikation eine wesentliche Rolle. Ohne den übergreifenden Sinnzusammenhang des Gesamtreiches und die symbolischen Ressourcen, die Regnum (später auch Imperium), Gens und Ecclesia boten, wäre diese Form der Integration von Eliten aber nicht möglich gewesen.

- Achtens erlaubten es Konflikte (nicht nur durch ihre rituelle Bewältigung), die Machtverhältnisse innerhalb eines Reiches auf die Probe zu stellen und gerade dadurch letztlich zu bestätigen. Selbst wenn die Zentralmacht daraus geschwächt hervorging, der staatliche Zusammenhang war davon nicht notwendigerweise betroffen.

- Neuntens konnte die Zentralgewalt mehr oder weniger erfolgreich auf ökonomische, personelle und militärische Ressourcen zurückgreifen, auch wenn das weitgehende Fehlen von Steuersystem, Bürokratie und stehendem Heer diesen Zugriff erschwerte.

190 Siehe den Beitrag von Hans-Werner Goetz in diesem Band.

191 Siehe die Beiträge von Mayke de Jong und Steffen Patzold in diesem Band.

192 Michel Foucault, Die Ordnung des Diskurses (Frankfurt am Main 1991), bes. 11. Zur Rolle exegetischer Literatur in politischen Auseinandersetzungen Mayke de Jong, Bride-shows revisited: praise, slander and exegesis in the reign of the Empress Judith, in: Gender in the Early Medieval World. East and West, 300-900, ed. Leslie Brubaker/Julia M. H. Smith (Cambridge 2004) 571-618; dies., Exegesis for an empress, in: Medieval Transformations. Texts, Power and Gifts in Context, ed. Esther Cohen/Mayke de Jong (Leiden/Boston/Köln 2001) 69-100; dies., The empire as ecclesia. 
- In all diesen Zusammenhängen agierten zehntens der König, aber auch andere Akteure, einerseits gemäß ihren jeweiligen sozialen Rollen, aber andererseits mit oft beträchtlichem Spielraum zum politischen Handeln, das zu Erfolg oder Mißerfolg führen konnte.

,Staat‘ im Früh- und Hochmittelalter war also kein geschlossenes, sondern ein offenes System, in dem sich ,Identität und Differenz' an zusammenhängenden, aber doch unterschiedlichen Gemeinschaftsformen und Sinnstrukturen orientierten: Königsherrschaft, ethnische Identität und kirchliche Einheit ermöglichten im Zusammenspiel, aber auch in Konkurrenz zueinander politische Integration. Diskursive Bemühungen ebenso wie politische Anstrengungen richteten sich darauf, sie als Aspekte ein- und derselben Gemeinschaft darzustellen, was vor allem in der Karolingerzeit Ziel umfassender ,Reform'-Bestrebungen war. Die moderne historische Kritik hat sich seit längerem vor allem darauf gerichtet, das Scheitern solcher Bemühungen zu zeigen und die widersprüchliche Vermischung von Reich, Volk und Kirche als Schwäche der früh- und hochmittelalterlichen Ordnung herauszuarbeiten. Der Macht der Mächtigen, so lautet das Urteil, hatte ein solcher ,Staat' wenig entgegenzusetzen. Vielleicht läßt sich darin jedoch auch ein Potential entdecken, das gerade durch die mehrdimensionale politische Ordnung Entwicklungsmöglichkeiten eröffnete. Das könnte auch helfen, auf die alte Frage ,Warum Europa? ${ }^{? 193}$ neue Antworten zu finden. Das lateinisch-christliche Europa fiel nach der ,Umwandlung der römischen Welt' nicht einfach zurück in archaische Barbarei. Neue Spielräume öffneten sich, die neue Spielregeln erforderten. Bei aller Vielgestalt blieben weiträumige Zusammenhänge gewahrt. Die politische Organisation des großen Raumes konnte auf solche Ressourcen zurückgreifen. Bis zum 11. Jahrhundert entstanden so jene politischen Identitäten, die das Europa des 2. Jahrtausends prägen sollten.

193 Siehe jüngst etwa Das europäische Mittelalter im Spannungsbogen des Vergleichs, ed. Michael Borgolte (Berlin 2001); Michael Mitterauer, Warum Europa? Mittelalterliche Grundlagen eines Sonderweges (München 2003). Neue Tendenzen der, global history“ versuchen demgegenüber, die europäische Expansion als spätes Produkt ökonomischer und politischer Zufälle zu erklären; siehe etwa Kenneth Pomerantz/Steven Topik, The World that Trade Created. Society, Culture and the World Economy, 1400 to the Present (Armonk, New York/London 1999). Eine teleologische Darstellung, die europäische Weltherrschaft als zwangsläufige Folge mittelalterlicher Ursprünge erklärt, sollte tatsächlich vermieden werden. Doch baut jede Gesellschaft Spannungen und Potentiale auf, die teils viel später wirksam werden. 